\title{
Do genes lie? Mitochondrial capture masks the Red Sea collector urchin's true identity (Echinodermata: Echinoidea: Tripneustes)
}

Omri Bronstein ${ }^{a, b, c}$, Andreas Kroh ${ }^{a}$ and Elisabeth Haring b,d

\author{
${ }^{a}$ Natural History Museum Vienna, Geological-Paleontological Department, Burgring 7, 1010 \\ Vienna, Austria \\ ${ }^{\mathrm{b}}$ Natural History Museum Vienna, Central Research Laboratories, Burgring 7, 1010 Vienna, \\ Austria \\ ${ }^{c}$ The Steinhardt Museum of Natural History and National Research Centre, Tel Aviv \\ University, Israel \\ ${ }^{d}$ University of Vienna, Department of Integrative Zoology, Vienna, Austria
}

E-mail addresses:

omribronstein@gmail.com (O. Bronstein)

andreas.kroh@nhm-wien.ac.at (A. Kroh)

elisabeth.haring@nhm-wien.ac.at (E. Haring)

\begin{abstract}
Novel $\mathrm{COI}$ and bindin sequences of the Red Sea collector echinoid Tripneustes gratilla elatensis are used to show that 1 ) discordance between mitochondrial and nuclear loci exists in this echinoid genus, 2) Tripneustes gratilla as currently defined possibly comprises a complex of cryptic species, and 3) Red Sea Tripneustes form a genetically distinct clade in the bindin tree, which diverged from other Tripneustes clades at least 2-4 million years ago. Morphological reassessment of $T$. gratilla elatensis shows perfect congruence between identification based on skeletal features and genetic data based on a nuclear marker sequence. Hence the Red Sea Tripneustes subspecies established by Dafni in 1983 is a distinct biological unit.
\end{abstract}


All T. g. elatensis samples analyzed are highly similar to or share mtDNA haplotypes with Philippine T. g. gratilla, as do representatives from other edge-of-range occurrences. This lack of genetic structure in Indo-Pacific Tripneustes is interpreted as a result of wide-spread mitochondrial introgression. New fossil specimens from the Red Sea area confirm the sympatric occurrence of $T . g$. elatensis and $T . g$. gratilla in the northern Red Sea during Late Pleistocene, identifying a possible timing for the introgression. In addition, present-day distribution shows a contact zone in the Southern Red Sea (in the Dahlak Archipelago).

T. g. elatensis, is yet another example of a Red Sea taxon historically identified as conspecific with its Indo-Pacific relatives, but which turned out to be a morphologically and genetically distinct endemic taxon, suggesting that the level of endemism in the Red Sea may still be underestimated.

\section{Keywords}

Molecular phylogeny

Biogeography

Mitochondrial capture

Integrative taxonomy

Toxopneustidae

Red Sea

\section{Introduction}

Understanding the forces that drive speciation in marine environments remains a challenging goal despite significant progress in recent years. High dispersal potential of organisms with planktonic larvae and lack of clear geographic barriers to gene flow between populations, greatly complicate our ability to reconstruct the chain of events leading to the formation of new species (McCartney et al., 2000; Palumbi, 1994). Owing to their relatively low number of extant species and to the existence of detailed alpha taxonomical studies, sea urchins had long been used as model organisms for the study of marine speciation (Mayr, 1954; Palumbi, 1996). Mayr (1954) extracted taxonomic and distributional information from Mortensen's (1928- 
51) "Monograph of the Echinoidea", and concluded that speciation in shallow water echinoids occurs allopatrically. However, since Mayr's pioneering work, several studies demonstrated the occurrence of species diversification even without clear geographic isolation (e.g., Coppard et al., 2013; Metz and Palumbi, 1996). Nonetheless, with time, geographic isolation is prone to give rise to highly diverged populations, and, owing to ecological speciation, this process may accelerate in areas of markedly different environmental conditions, such as those reported for the Red Sea (RS) during glacial cycles (DiBattista et al., 2016a).

The RS is a deep and narrow semi-enclosed body of water and is considered the world's northernmost tropical sea. It spans more than 2,200 km from the northern gulfs of Suez and Aqaba to the Strait of Bab-el-Mandeb in the south. The RS is a biogeographical region of exceptional high taxonomic diversity and high levels of endemism (see review by DiBattista et al., 2016b) and as such is referred to as a biodiversity hotspot. The latter authors report that $12.9 \%$ of fishes, $12.6 \%$ of polychaete, $8.1 \%$ of echinoderms, $16.5 \%$ of ascidians and $5.8 \%$ of scleractinian corals in the RS are endemic, making this region a hot spot for endemism with some of the highest levels of endemism recorded in the entire Indo-West Pacific. Such highly diverged peripheral regions as the RS, are also referred to as "evolutionary incubators" recognizing their important contribution of unique genetic lineages (Bowen et al., 2013; DiBattista et al., 2013; Malay and Paulay, 2010; Skillings et al., 2011). The geological history of the RS and its potential isolation barriers have been discussed by DiBattista et al. (2016a). The history of the RS dates back to the Late Cretaceous, but it was not until 5 to 4 million years ago (Ma) that conditions in the RS stabilized from the early unfavorable, highly saline environment, to facilitate the proliferation of marine fauna during the Pliocene and Pleistocene (4 to $3 \mathrm{Ma}$ ) when also a more permanent connection to the Indian Ocean (IO) was consolidated (Bailey et al., 2007). Except for the man-made Suez Canal completed in 1869, connecting the RS with the Mediterranean Sea at the northern tip of the Gulf of Suez, the narrow and shallow Strait of Bab-el-Mandeb (29 km and $137 \mathrm{~m}$, respectively), constitute the only connection of the RS to the IO (Bailey, 2009). This topographical setup renders the RS susceptible for isolations during periods of low sea level that are often associated with glacial maxima (Ludt and Rocha, 2015; Rohling et al., 2009). The latest such occasion is believed to have occurred during the Last Glacial Maximum, ca. 20 to $15 \mathrm{ka}$ ago when sea level dropped by $115 \mathrm{~m}$ (Ludt and Rocha, 2015; Siddall et al., 2003). Moreover, the monsoonal-driven cold-water upwelling off the coasts of Somalia and Oman (reaching temperatures as low as $13^{\circ} \mathrm{C}$; Currie et al., 
1973; Smeed, 1997) is believed to act as yet another isolating barrier for the RS fauna (Kemp, 1998, 2000). Regardless of the mechanism of isolation, different basins within the RS experienced significantly different environmental conditions during periods of isolation. Of these conditions, hyper-salinity is acknowledged as the major driver of extinction (Kinsman, 1964; Por, 1972, 2008). Interestingly, estimations based on planktonic foraminiferans suggest that salinity in the Gulf of Aqaba (GOA) remained within tolerable levels of below 45\%, at times when the rest of the RS Basin experienced hyper-saline conditions of ca. 55-57\%o (Fenton et al., 2000; Thunell et al., 1988), suggesting the GOA may have served as refugium for RS fauna (DiBattista et al., 2016a).

Sea urchins of the genus Tripneustes L. Agassiz, 1841 are some of the most common and widespread shallow-water echinoids (Lawrence and Agatsuma, 2013). Within this genus three extant species are currently recognized: the Indo-Pacific Tripneustes gratilla (Linnaeus, 1758), the eastern Pacific Tripneustes depressus (A. Agassiz, 1863), and the Atlantic Tripneustes ventricosus (Lamarck, 1816) (Mortensen, 1928-51). Due to their wide circum-tropical distribution and high abundance at the sites were they occur, these species received much attention in the scientific literature including detailed studies of their ecology (Lawrence and Agatsuma, 2013; Mortensen, 1928-51; Vonk et al., 2008), growth (Dafni, 1992; McPherson, 1965), behavior (Amato et al., 2008; Kehas et al., 2005), and reproduction (Chen and Chang, 1981; Muthiga, 2005; Pearse, 1974; Vaïtilingon et al., 2005). Furthermore, due to their fast growth rate and high market value, Tripneustes are also highly valued by the fisheries and aquaculture industry (Mos et al., 2012).

High interspecific similarity in this genus, with only minor morphological characteristics to distinguish the species (Mortensen, 1928-51), led some workers to suggest that they are probably but a single species (Clark, 1912). These claims are in part supported by later studies incorporating molecular genetic evidence that, while ratifying the taxonomic status of $T$. ventricosus, question the validity of treating T. gratilla and T. depressus as two separate species (Lessios et al., 2003). Of all Tripneustes species, $T$. gratilla is the most common and widespread species, ranging from the East-Pacific to East Africa and the RS and from the Kermadec Islands (New Zealand) to Japan (Lawrence and Agatsuma, 2013). However, across its vast range, T. gratilla shows considerable morphological variability and representatives from the $\mathrm{RS}$ are morphologically distinct from other $T$. gratilla populations. These differences include sparse inter-ambulacral tuberculation, compressed shape of the corona 
(lower height), larger peristome, fewer inter-ambulacral plates and distinct coloration (Dafni, 1983). Consequently, a new subspecies was proposed for the RS population: T. gratilla elatensis Dafni, 1983. Phylogeographic studies of Tripneustes, targeting populations across their range, demonstrated a lack of phylogenetic structure in mitochondrial (mt) DNA (Lessios et al., 2003; Liggins et al., 2014). Zigler and Lessios (2003) studied variation of the nuclear bindin gene (coding for a gamete recognition protein) in Tripneustes from the Pacific, Atlantic, and Indian oceans. They found that the Atlantic T. ventricosus differed from the eastern Pacific T. depressus and the Indo-West Pacific T. gratilla, but found no differences between the bindins of $T$. depressus and T. gratilla, nor any geographic structure in the distribution of bindin alleles. Lack of phylogeographic structure and haplotype sharing between widely distant localities as the Philippines, Kermadec Island and the Galapagos Islands is suggestive of recent radiation and high dispersal potential. However, Tripneustes from the RS and Gulf of Aqaba have never been studied and illustrated in a modern taxonomical manner and were not included in any of the phylogeographic studies of the genus (e.g., Lessios et al., 2003; Liggins et al., 2014; Zigler and Lessios, 2003). Thus, the taxonomic status of the northern RS subspecies $T$. gratilla elatensis and its relation to the two mt clades of Tripneustes are currently unclear.

In discussing phylogenies and species delimitation it is important to discern two fundamental concepts: phylogenetic (species) trees and gene trees. Phylogenetic trees are defined as the branching pattern of species lineages via the process of speciation, while gene trees are contained within species trees and represent the branching pattern of a single locus in the genome (Maddison, 1997). Consequently within a species, many gene trees can be found and a subset of those can potentially disagree with their underlying species trees. To mitigate the potential risk of drawing erroneous phylogenetic conclusions, multiple independent genetic markers including loci both of the mt genome (mtDNA) and the nuclear genome (nuDNA) are commonly used (Avise, 1994). Of all genetic markers, mitochondrial genes have long served as the markers of choice for phylogeographic and specieslevel phylogenetic analyses (Avise, 2000). Analyses based on mitochondrial data often provide robust phylogenetic and phylogeographic estimates, however, under certain circumstances, a mitochondrial gene tree may fail to reflect phylogenetic descent properly (Doyle, 1997; Nichols, 2001), but rather reveal other evolutionary processes such as introgressive hybridization (Funk and Omland, 2003; Maddison, 1997; Ruedi et al., 1997). If left undetected, such processes may confound phylogenetic inference (Leaché and McGuire, 2006), however, if the signatures of 
these processes are recognized, their occurrence can provide insights into the evolutionary process that would otherwise remain undetected (McGuire et al., 2007).

Here we combine genetic ( $\mathrm{mt}$ and $\mathrm{nc}$ ), morphological, paleontological and ecological data to resolve the taxonomic status and reconstruct the phylogeny of RS Tripneustes. We provide a taxonomic re-evaluation of RS Tripneustes, and present the first genetic data for Tripneustes from this region. We then use these data to explore the forces shaping the evolutionary history of RS Tripneustes, which also provides new insights relevant to the phylogeny and taxonomy of Tripneustes as a whole.

\section{Materials and methods}

\subsection{Study area and sample collection}

Specimens of Tripneustes where collected around the world at depths of 0.5 to 10 meters (Fig. 1). All tissue samples were fixed and preserved in 96\% molecular grade $\mathrm{EtOH}$. Table S1 gives an overview of all analyzed samples and lists sample names, collection locations, GenBank accession numbers and the source of the data. Specimens have been collected under permit numbers: (1) 2014/40622 issued on October $20^{\text {th }} 2014$ by Israel Nature and National Parks Protection Authority, (2) TAFIRI HQ/BIW/Vol.III/103 issued on August $31^{\text {st }} 2014$ by The Permanent Secretary, Ministry of Livestock and Fisheries Development, Dar Es Salaam, Tanzania, and (3) Gratuitous Permit numbers GP-0077-14 and GP-0085-15, made available in accordance with a material transfer agreement between the Natural History Museum Vienna and the California Academy of Sciences (CAS).

\subsection{DNA extraction, PCR and sequencing}

Total genomic DNA was extracted from spine muscle or tube feet tissue using Promega's Tissue and Hair Extraction Kit used in conjunction with the DNA IQTM System (Promega Corporation, WI, USA) following manufacturer's instructions. Two molecular markers were analyzed: the $\mathrm{mt}$ cytochrome c oxidase subunit I gene (COI) and the nu bindin gene (partial sequences of two exons and the intervening intron).

Three primer pairs were used to amplify up to three overlapping fragments of the $\mathrm{COI}$ gene (Table 2), covering and adding on the existing published $\mathrm{COI}$ 
sequence data for Tripneustes (Liggins et al., 2014; Zigler and Lessios, 2003). The largest COI amplicon (primers TripCOI1+ / TripCOI5-) had a length of 1168 bp. For details on the other fragments see Supplementary Material. In total, Tripneustes sequences from 23 RS, 6 Western Indian Ocean (WIO) and 9 Western Pacific individuals have been obtained. Polymerase chain reactions (PCR) were performed in $25 \mu \mathrm{l}$ using $1 \mu \mathrm{l}$ DNA (10-15 ng), $2.5 \mu \mathrm{l}$ 10X AmpliTaq Gold ${ }^{\circledR} 360$ Buffer (Applied Biosystems), 2 nM Magnesium Chloride, $1 \mu \mathrm{l} 360$ GC Enhancer, 0.2 mM dNTPs, 0.1 $\mu \mathrm{M}$ of each primer, and 1.25 units AmpliTaq Gold ${ }^{\circledR} 360$ DNA Polymerase. PCR conditions consisted of an initial denaturation step at $95^{\circ} \mathrm{C}$ for 5 min followed by two cycles of $\left[95^{\circ} \mathrm{C}\right.$ for $15 \mathrm{~s}, 60^{\circ} \mathrm{C}$ for $30 \mathrm{~s}$ and $72{ }^{\circ} \mathrm{C}$ for $70 \mathrm{~s}$ ], additional 38 cycles of [ $95^{\circ} \mathrm{C}$ for $15 \mathrm{~s}, 56^{\circ} \mathrm{C}$ for $30 \mathrm{~s}$ and $72{ }^{\circ} \mathrm{C}$ for $70 \mathrm{~s}$ ], and a final extension step at $72{ }^{\circ} \mathrm{C}$ for $7 \mathrm{~min}$. For amplifications using the primer pair TripCOI1+/TripCOI4- or TripCOI3+/TripCOI5-, 40 cycles of single step PCRs were applied differing only in the annealing temperatures $\left(62{ }^{\circ} \mathrm{C}\right.$ and $54^{\circ} \mathrm{C}$, respectively). Amplified fragments were visualized on 1\% agarose gels and purified using the QIAquick PCR Purification Kit (QIAGEN) according to the manufacturer's protocol. Direct sequencing (in both directions) was performed at LGC Genomics (Berlin, Germany) using PCR primers. COI sequences are deposited in GenBank under the accession numbers KU314827 to KU314864.

Bindin sequences were obtained from 28 specimens: 11 from RS, 5 from the WIO, and 12 from the Western Pacific. The complete target sequence ( 1613 bp) was amplified with primers Tripbin1a+ / Tripbin3a- (Table 2). PCR reactions were performed in $25 \mu \mathrm{l}$ containing $2 \mu \mathrm{l}$ DNA (10-15 ng), $2.5 \mu \mathrm{l}$ 10X High Fidelity PCR Buffer, $2 \mathrm{mM} \mathrm{MgSO}_{4}, 0.2 \mathrm{mM}$ dNTPs, $0.2 \mu \mathrm{M}$ of each forward and reverse primer, and 0.5 units Platinum ${ }^{\circledR}$ Taq High Fidelity polymerase. PCR conditions were 2 min at $94{ }^{\circ} \mathrm{C}, 2$ cycles $\left[94^{\circ} \mathrm{C}\right.$ for $15 \mathrm{~s}, 62^{\circ} \mathrm{C}$ for $30 \mathrm{~s}, 68^{\circ} \mathrm{C}$ for $90 \mathrm{~s}$ ] followed by 35 cycles [94 ${ }^{\circ} \mathrm{C}$ for $15 \mathrm{~s}, 53^{\circ} \mathrm{C}$ for $30 \mathrm{~s}, 68^{\circ} \mathrm{C}$ for $90 \mathrm{~s}$ ]. PCR products were sequenced directly at LGC Genomics (Berlin, Germany) using the primers Tripbin1a+, Tripbin3a, Tripbin5+ and Tripbin4-. Sequences with double peaks in chromatograms were cloned prior to sequencing (for details see Supporting Information). Bindin sequences are deposited in GenBank under the accession numbers KU355756 to KU355783. 


\section{Table 1}

Primer sequences for amplification and sequencing of the $\mathrm{CO}$ and bindin fragments.

\begin{tabular}{|l|l|l|}
\hline Primer sets & & \\
\hline Region & Primer name & Sequence (5' to 3') \\
\hline COI (fwd) & TripCOI1+ & GCCTGAGCCGGAATGGTAGG \\
\hline COI (rev) & TripCOI5- & ACCTTTCCTCATAGAGGGTG \\
\hline COI (internal fwd) & TripCOI3+ & TCTTTACCAGTTCTAGCAGG \\
\hline COI (internal rev) & TripCOI4- & TCTCCTCCGCCTGCTGGGTC \\
\hline Bindin (fwd) & Tripbin1a+ & CCCAGAAATTTCGGACGATT \\
\hline Bindin (rev) & Tripbin3a- & CCTTGCCGATAACCCTGATTGT \\
\hline Bindin (internal rev) & Tripbin2- & TGGTAGGTCAATCTTCGTGG \\
\hline Bindin (internal rev) & Tripbin4- & TACCTATTTCACAAAGTGGC \\
\hline Bindin (internal fwd) & Tripbin5+ & AATACAGTTCAGCTAGCACCG \\
\hline
\end{tabular}

\subsection{Sequence statistics and phylogenetic tree reconstruction}

Phylogenetic analyses were based on the $\mathrm{CO}$ and bindin datasets. In order to facilitate the integration of our sequences with previously published data, three $\mathrm{COI}$ datasets were created: the first contained 37 full length COI sequence (1126 bp after sequence editing) with Strongylocentrotus purpuratus as outgroup. The second (531 bp long) containing 23 T. g. elatensis and 34 T. g. gratilla sequences plus an additional $14 T$. ventricosus, 6 T. depressus and Lytechinus variegatus serving as outgroup (see tables S1 and S2 for details), and a third (449 bp long) comprising our data plus an additional 289 comparable Tripneustes COI sequences from the literature yielding 328 sequences in total: 23 T. g. elatensis, 35 T. depressus, 201 T. g. gratilla, 22 Tripneustes of uncertain specific identity, and 47 T. ventricosus, Table S2). Similarly, our full length bindin alignment (comprising two partial exons and an intron; 1613 bp) was used to compile two datasets; one ("bin-compl"; $1186 \mathrm{bp}$ ), contained parts of both exons and the intron after removal of gaps and ambiguous sites. The second dataset ("bin-exons"; 539 bp) was prepared without the intron (857-881 bp) which could not be unambiguously aligned with sequences of outgroup taxa. When applicable, Lytechinus variegatus was used as outgroup (i.e., for the Bin- 
exons and for the COI subset datasets) since this genus has been identified as a sister taxon of Tripneustes (Smith and Kroh, 2013; Zigler and Lessios, 2003).

Raw sequences were aligned automatically using ClustalX v2.1 (Larkin et al., 2007) and edited manually using Bioedit v.7.1.3 (Hall, 1999). Median-Joining networks were calculated for the $449 \mathrm{bp} \mathrm{COI}$ dataset with PopArt (Leigh and Bryant, 2015) applying the default settings. For the other datasets positions with gaps were removed using TrimAl v.1.4 (Capella-Gutiérrez et al., 2009) and identical sequences identified using DAMBE v.6.0.1 (Xia, 2013). Our 39 de-novo COI 531 bp sequences collapsed into 16 haplotypes to which an additional 17 unique haplotypes from the other Tripneustes species were added and L. variegatus served as outgroup. Our 28 sequences of the full length bindin collapsed into 27 haplotypes and an additional 15 unique sequences of the other Tripneustes species were added. Phylogenetic reconstructions were performed using both the maximum likelihood (ML) method and Bayesian inference (BI). ML analyses were all performed with RAxML v.7.2.6 (Stamatakis, 2006) while $\mathrm{BI}$ analyses were conducted with MrBayes v.3.2.2 (Ronquist and Huelsenbeck, 2003). Partitions and optimal substitution models were determined for all individual data sets using the Bayesian information criterion (BIC) metric for model selection (Schwarz, 1978) in PartitionFinder v.1.1.1 (Lanfear et al., 2012). COI datasets were partitioned according to codon positions. The best-fitting substitution models for the 531 bp $\mathrm{COI}$ datasets were $\mathrm{GTR}+\mathrm{G}$ and $\mathrm{HKY}+\mathrm{I}$ (on all codon positions) for $\mathrm{ML}$ and $\mathrm{BI}$, respectively. The bindin gene was partitioned by $1^{\text {st }}$ and $2^{\text {nd }}$ exons, the intron, and codon positions. For both bindin datasets (bin-compl and bin-exons) the best fitting model for the ML analyses was the GTR+G model. For the $\mathrm{BI}$ analyses the $\mathrm{HKY}+\mathrm{G}$ and $\mathrm{K} 80$ substitution models were found best fitting for the bin-compl and bin-exons datasets, respectively.

RAxML tree reconstructions were carried out using 100 random starting trees. Branch support was computed based on 1000 bootstrap replications. Analyses in MrBayes were calculated for each of the datasets according to the respective data partitions. Applying the respective model parameters, the analyses were run for 10 million generations each (2 runs with 4 chains, one of which was heated), sampling every $100^{\text {th }}$ tree. Convergence was assessed according to the average standard deviation of split frequencies $<0.01$. The runs were also visually checked by plotting generations vs. likelihood scores and in Tracer v.1.6 (Rambaut et al., 2013) to assess whether the two runs had converged and when the stationary phase was reached. In a conservative approach, the first $25 \%$ of trees were discarded as burn-in 
and a $50 \%$ majority rule consensus tree was calculated from the remaining 75,000 trees.

Based on the bin-compl dataset, uncorrected mean p-distances and Kimura twoparameter (K2P; Kimura, 1980) genetic distances were calculated within and between species / clades using MEGA v.6.0.6 (Tamura et al., 2013). BEAST v.1.8.2 (Drummond and Rambaut, 2007) was used to estimate the timing of divergence of the different bindin clades based on both the bin-compl and the bin-exons datasets. The relative rate variation among lineages was tested separately for each dataset with the molecular-clock test implemented in MEGA v.6.0.6 (Tamura et al., 2013) applying the best fitting substitution models for each of the datasets (which are the same as used in the respective $\mathrm{BI}$ analyses). Since the null hypothesis of equal evolutionary rates throughout the trees were rejected at a $5 \%$ significance level ( $P$ $=0$ ), divergence times were estimated under a relaxed molecular-clock. Following previous studies investigating trans-Isthmian speciation in echinoids (Lessios et al., 2012; Coppard et al., 2013) the divergence times of the bindin lineages were estimated based on the split between the Atlantic and the Pacific Tripneustes set to $2.95 \pm 0.15 \mathrm{Ma}$, assuming their separation at the latest at the time of the closure of the Isthmus of Panama (Coates and Obando, 1996; Coates et al., 2003). While the exact timing of the closure and establishment of an effective barrier to gene flow has recently been questioned (see Bacon et al. 2015a, b; Lessios, 2015; Marko et al., 2015), the date used herein represents the final closure and thus will result in minimum divergence ages. Settings in BEAUti v.1.8.2 (part of the BEAST package) included the best fitting substitution models for each dataset, implementing the Yule Process (Gernhard, 2008) speciation model. The BEAST analyses were each performed independently four times for $10^{7}$ generations sampling every $1000^{\text {th }}$ tree. Convergence of the runs was checked using Tracer v.1.6 (Rambaut et al., 2013), and combined with LogCombiner v.1.8.2 (part of the BEAST package). Subsequently, $25 \%$ of the trees were discarded as burnin and maximum clade credibility trees were calculated each from the remaining 30,000 trees. The secondary structure of the bindin intron was predicted using RNAstructure v.5.8 (Reuter and Mathews, 2010).

\subsection{Morphological analysis}

In order to account for true interspecific morphological differences rather than ontogenetic variation, RS Tripneustes specimens ranging from very young, newly 
settled individuals $(2.6 \mathrm{~mm}$ in diameter) to fully mature specimens $(72.8 \mathrm{~mm}$ in diameter) were studied and compared to T. gratilla specimens from Tanzania and the Philippines. External appearance and coloration patterns (epidermis, pedicellariae, spines, and tube-feet) were noted for each specimen. The skeletal components (corona, plates, tuberculation, etc.) of selected specimens were assessed following removal of the soft tissue. This was done using enzymatic digestion of the soft tissue with Enzyrim (Bauer Handels $\mathrm{GmbH}$, Germany) following the manufacturers protocol. Measurements of both the corona (height and diameter) and peristome were performed using digital Vernier calipers to the nearest $0.1 \mathrm{~mm}$. Skeletal elements of the jaws were observed and measured under a Scanning Electron Microscope (SEM) (JEOL, JSM-6610LV) at the Central Research Laboratories of the Natural History Museum in Vienna, Austria. The type material of T. g. elatensis, deposited in the Hebrew University of Jerusalem (voucher number: HUJEc1) was examined and compared to the newly collected material. In addition, several public and private collections were screened for fossil Tripneustes specimens from RS Late Pleistocene raised reef terraces (Mansour et al., 2015). Fossil specimens used in the present study were deposited at the NHMW (collection of the Department of Geology and Paleontology).

\section{Results}

\subsection{Phylogeny}

The phylogenetic estimates obtained here were generally in agreement with respect to previously published assessments. However, as RS Tripneustes were never investigated using molecular tools its placement within Tripneustes is discussed here for the first time. Below we present the results of both $\mathrm{ML}$ and $\mathrm{BI}$ analyses for the mt and nc markers, respectively.

\subsection{1. $\mathrm{mtDNA}$}

$\mathrm{BI}$ and $\mathrm{ML}$ analyses produced congruent phylogenies for all clades and subclades and thus only $\mathrm{BI}$ inferred topologies are presented (Fig. 3 and Fig. S1). Phylogenetic reconstructions based on the $\mathrm{mt} \mathrm{CO}$ datasets failed to provide a clear structure in compliance with either the geographical distribution or morphological attribution of known Tripneustes. T. g. elatensis form the RS appeared polyphyletic 
and nested within clades or shared haplotypes with the IWP T. g. gratilla (Fig. 3 and Fig. S1). The 531 bp COI dataset was constructed in an attempt to gain further insights on the phylogenetic framework of Tripneustes, accommodating comparisons of our newly generated sequences with the other known species of Tripneustes as well as to facilitate the rooting of the subsequent phylogenies. Rooting with Lytechinus variegatus, only the monophyly of $T$. ventricosus was strongly supported (Fig. 3, clade 2). T. depressus (Fig. 3, clades 4 and 6) as well as the RS Tripneustes (Fig. 3, clades 3 and 5) appear to be polyphyletic and nested within the widely distributed T. g. gratilla (Fig. 3, clade 1). The mt diversity of Tripneustes was further explored by displaying the distributional patterns of the $\mathrm{COI}$ haplotypes through a Median joining haplotype network (Fig. 4). Similarly to the topologies of the trees, the $\mathrm{COI}$ network is clearly divided into two clusters of haplotypes: the first includes all Atlantic haplotypes. The second cluster is formed by Pacific Tripneustes. Haplotypes of both $T$. depressus and T. g. elatensis are embedded within the large variety of $T$. g. gratilla haplotypes, and both share haplotypes with $T$. g. gratilla. Thus, neither $T$. depressus nor T. g. elatensis could be delimited from T. g. gratilla based on their $\mathrm{mt}$ COI sequences.

\subsection{2. nuDNA}

With bindin sequences, both $\mathrm{BI}$ and $\mathrm{ML}$ analyses yielded compatible tree topologies for all clades and subclades, and thus we again present the $\mathrm{Bl}$ inferred topologies only. Similarly to the topologies inferred by $\mathrm{COI}$, the resulting trees recovered $T$. ventricosus as a strongly supported clade (Fig. 5 and Fig. S2, clade E). The analyses also recovered the RS T.g. elatensis as a well-supported monophylum (Fig. 5 and Fig. S2, clade C). However, the bin-compl dataset also revealed that Tripneustes is split into two distant lineages comprising of $T$. ventricosus + a subset of $T$. g. gratilla specimens and T. g. elatensis + another subset of $T$. g. gratilla specimens (including all $T$. depressus) (Fig. 5 , clades $E+D_{1,2}$ and clades $A_{1,2}+C$, respectively). The RS Tripneustes clade is the sister group of the T. g. gratilla $+T$. depressus clade (Fig. 5 clades $A_{1}+A_{2}$ and Fig. S2, clade $A$ ), the later once again nested within T. g. gratilla (Fig. 5 and Fig. S2, clade B). Surprisingly, in all analyses, T. g. gratilla was not recovered as a monophylum, but is rather polyphyletic, as it occurs in several (partially highly supported) clades. One of these clades represents the sister group of $T$. ventricosus (Fig. 5, clade $D_{1,2}$ ), while the other (Fig. 5, clades $A_{1}+A_{2}$ ) clustered to form a sister group to $T$. g. elatensis. The later cluster was further 
diverged into a branch containing $T$. g. gratilla taxa only (Fig. 5, clade $A_{2}$ ), and a branch containing T. g. gratilla and T. depressus specimens (Fig. 5, clade $A_{1}$ ). Divergence within the $T . g$. elatensis clade was low $(0.4 \%$ mean K2P divergence) based on the bin-compl dataset, similar only to the divergence within $T$. ventricosus (Table 2). The intraspecific divergence within the clades of $T$. g. gratilla were 3-4 times higher than those of $T$. g. elatensis $(1.1 \%$ and $1.5 \%$ vs. $0.4 \%$, respectively). Interspecific divergence between T. g. elatensis and the other Tripneustes clades ranged from $3.4 \%$ to $3.6 \%$ and was comparable to the divergence recorded between T. ventricosus and $T$. g. gratilla clade $\mathrm{A}_{1+2}(3.6 \%)$. T. ventricosus and the basal $T$. $g$. gratilla clade $\mathrm{D}_{1+2}$ (Fig. 5) were the least diverged, showing only $2.4 \%$ genetic divergence.

The molecular clock estimations of minimum divergence dates based on the bincompl dataset (Fig. S4) date the branching of T. g. elatensis at 3.74 Ma (2.04-5.6 Ma., 95\% highest posterior density [HPD] interval). This split predates the divergence between $T$. ventricosus and the Pacific clades of $T$. g. gratilla (Fig. 5). The most basal split separating the $T$. ventricosus $+T$. g. gratilla clade $D$ from the remaining clades was estimated to 4.63 Ma (2.99-6.6 Ma, 95\% HPD).

\section{Table 2}

Intraspecific and interspecific distances (in percent) within Tripneustes based on the bincompl dataset. Ranges and means (in brackets) of p-distances between (above diagonal) and within (diagonal, after slash) groups as well as K2P distances between (below diagonal) and within (diagonal before slash) groups are shown. Letters in brackets correspond to the clades in Fig. 5.

\begin{tabular}{|c|c|c|c|c|}
\hline & T. g. elatensis (C) & $\begin{array}{l}\text { T. g. gratilla }+T . \\
\text { depressus }\left(\mathrm{A}_{1}+\mathrm{A}_{2}\right)\end{array}$ & T. g. gratilla $\left(\mathrm{D}_{1}+\mathrm{D}_{2}\right)$ & T. ventricosus (E) \\
\hline T. g. elatensis (C) & $\begin{array}{c}0.1-0.7(0.4) / \\
0.1-0.7(0.4)\end{array}$ & $3.0-3.8(3.4)$ & $3.2-3.8(3.5)$ & 3.2-3.9 (3.6) \\
\hline $\begin{array}{l}\text { T. g. gratilla }+T . \\
\text { depressus }\left(\mathrm{A}_{1}+\mathrm{A}_{2}\right)\end{array}$ & $3.1-3.8(3.5)$ & $\begin{array}{c}0.1-2.4(1.1) / \\
0.1-2.6(1.2)\end{array}$ & $2.6-4.4(3.4)$ & $3.2-4.4(3.7)$ \\
\hline T. g. gratilla $\left(\mathrm{D}_{1}+\mathrm{D}_{2}\right)$ & $3.1-3.6(3.4)$ & $2.3-4.4(3.2)$ & $\begin{array}{l}0.1-3.0(1.5) \\
/ 0.2-3.1(1.6)\end{array}$ & $1.7-3.4(2.4)$ \\
\hline T. ventricosus $(\mathrm{E})$ & $3.3-3.9$ (3.6) & $3.0-4.3(3.6)$ & $1.7-3.4(2.4)$ & $\begin{array}{c}0.2-0.7(0.4) \\
/ 0.1-0.7(0.4)\end{array}$ \\
\hline
\end{tabular}




\subsection{Unique sequence traits}

Alignments of the bindin sequences of RS T. g. elatensis with the other Tripneustes species revealed a unique $30 \mathrm{bp}$ long insertion in the first exon (Table S3). This sequence feature, coding to amino acids 5'-GPVGGGGNMG-3', is part of a glycine-rich repeat $G(P / Q / S)(V / G) G G G(G / S)(N / G)(M / R / E / G)(G / E)$. Similar glycinerich motifs have also been reported from bindin genes of other camarodont (e.g., Echinometra and Strongylocentrotus, see discussion in Zigler and Lessios, 2003). Two copies of this repeat are present in T. ventricosus, three in all IWP T. g. gratilla (including $T$. depressus) except for RS Tripneustes, which have four copies. The region was excluded in the $\mathrm{ML}$ and $\mathrm{BI}$ analyses.

In addition, the 5 '-end of the bindin intron appears highly divergent between RS Tripneustes and other members of the genus. In T. ventricosus and T. g. gratilla we identified [using RepeatMasker and Censor (Kohany et al., 2006)] this part of the intron consistently as a 148-bp-long transposon named $D N A-1-2$ _SP, which was originally discovered by Bao and Jurka (2008) in Strongylocentrotus purpuratus. Interestingly, it is reverse in $T$. ventricosus and T. g. gratilla clades $D_{1}$ and $D_{2}$ (Fig. 5; see also Table S3), but normal in the two other T. g. gratilla clades (Fig. 5, clades $A_{1}$ and $\mathrm{A}_{2}$ ). In RS Tripneustes, in contrast, we identified a highly divergent sequence comprising an inverted 169 bp-repeat at the same position (426 to 594, following the positions on the supplementary alignment, S6). This inverted repeat may form a secondary hairpin structure (Fig. S3). As with the unique insertion in the first exon, this inverted repeat was present in all RS specimens but never appeared in any of the other Tripneustes populations. This portion of the intron was excluded from all further analyses.

\subsection{Morphology}

\subsubsection{Skeletal features}

Dafni (1983) established T. g. elatensis for northern RS Tripneustes populations that showed A) a more compressed corona, B) a larger peristome, C) fewer interambulacral plates, D) sparser interambulacral tuberculation and E) more vivid coloration than Indo-Pacific T. g. gratilla. Based on our comparison of the surviving type material and new RS samples with Tripneustes from Tanzania and the Philippines we can confirm Dafni's observations. In addition, several further 
differences were observed: 1) missing primary tubercles also on aboral ambulacral plates (very regular occurrence of primary tubercles are on every $3^{\text {rd }}$ plate in $T . g$. gratilla); 2) peristomal margin level with oral surface (sunken in T. g. gratilla); 3) periproctal opening larger at same test diameter (10.3-12.0\% of test diameter in T. g. elatensis vs. $7.1-10.1 \%$ in Tanzanian T. g. gratilla); 4) ambital poriferous zones slightly wider (31.0-36.0\% of ambulacrum width in T. g. elatensis vs. $25.8-31.7 \%$ in Tanzanian T. g. gratilla); 5) distal compass elements more robust, flattened in cross section and less strongly bifurcated vs. delicate, round cross-section and deep bifurcation in T. g. gratilla; Fig. 6I-L vs. 6M-P). Together with Dafni's original features these characters allow confident recognition of $T . g$. elatensis, even for fragmented and/or fossil material (e.g., such as those illustrated by Nebelsick, 1992: pl. 3, fig. 4 or Ragaini, 1997: pl. 1, fig. 4).

\subsubsection{Identification in the field}

Distinction of $T . g$. gratilla and T. g. elatensis in the field or based on images of live specimens is often easier than recognition of preserved specimens. While color in general is highly variable in both forms (see below and Dafni, 1983), distribution of spines and pedicellariae is not. Representatives of T. g. gratilla from Eastern Africa and the Philippines appear very spiny and typically have numerous spines of similar length that are held erect; only the midline of the interambulacra is free of large spines. This area is densely covered with globiferous pedicellariae, as is the midline of the ambulacra, while the pore zones are largely free of pedicellariae. This, together with epidermis color, causes a striking pattern of dark and bright bands in most specimens. In T. g. elatensis, in contrast, this pattern never is developed and pedicellariae form a dense cover all over the aboral corona, including the pore zones, apical disc and peristomal membrane. The spine cover appears much reduced, and the few large spines present typically are held oblique, protecting adjacent pore zones and the apical disc. The interambulacral areas thus look almost naked (except for the pedicellariae). This often causes a distinct subpentagonal appearance in aboral view. When disturbed (e.g., by removal of the camouflaging debris) T. $g$. elatensis tends to extend all of its tube feet in all directions - up to half the corona diameter, a behavior we have rarely seen in $T$. g. gratilla.

\subsubsection{Color}

All Tripneustes populations studied so far show distinct color polymorphism (e.g., Toha et al., 2015). In T. g. elatensis three main epidermis colors are common: "white" (not pigmented), red and black. Typical spines colors are white, white with red distal 
half, fully red and black; often primary and secondary spines show different coloration. Pedicellariae are usually white or light grey (in specimens with black epidermis). Tube feet either are uniformly clear/whitish or black, less commonly red (in the distal half). Almost any combination of epidermis, spine, pedicellarial and tube feet color is possible. Some combinations, however, seem to be more common than others: almost completely white and completely black specimens, as well as greenish individuals with red spines and dark individuals with red spines were particularly abundant at the study sites in the Gulf of Aqaba and Egypt. Juveniles, in contrast, (up to ca. $20 \mathrm{~mm}$ diameter) typically all are more or less uniformly light grayish green, sometimes with a brown tinge, which makes them hard to find in the field, where they usually cling to the undersides of rocks or dead corals. Upon preservation most of the coloration is lost and alcohol preserved specimens usually are pale cream or grayish black.

T. g. gratilla from the Philippines and Zanzibar usually have either white or black epidermis. Their spines are white, orange (rarely red) or black, often showing different coloration in ambulacral and interambulacral areas. Again, secondary spines may differ from primary ones in color. Pedicellariae usually are black, but can appear fluorescent dark blue in photographs. Tube feet, like in T. g. elatensis, are mostly white or black, but in T. g. gratilla white tubefeet often show a striking black band ca. halfway along their length (when extended) and lack pigment in the proximal half, creating a very distinct appearance. As in the former species, almost any combination of these colors is possible, but dark specimens with bright vertical bands and whitish specimens with dark vertical bands are most common, as are dark specimens with orange interambulacral primary spines. In T. g. elatensis we never observed banded tubefeet.

\subsection{Fossil occurrences}

Apart from a single exceptional site in the Early Miocene of France (Bongrain, 2013) members of the genus Tripneustes are usually found in form of isolated plates and spines, owing to their rapid disarticulation after death. Greenstein (1991) reports that under field conditions $T$. ventricosus is reduced to bleached skeletons devoid of tissue within six days. Unless rapidly embedded by sediment such bleached coronas are particular susceptible to further decay and usually disintegrate upon transport (Kier, 1977; Greenstein, 1993). Consequently, remains of Tripneustes are typically rare in sediments, even in areas where large populations exist in adjacent modern habitats (Gordon and Donovan, 1992; Nebelsick, 1992; Greenstein, 1993). 
Sometimes, however, fossil reefs provide abundant fissures and cavities in which fragile echinoid coronas may be trapped and preserved. Screening public and private collections of material from the Pleistocene fringing reefs exposed along the Egyptian RS coast we were able to locate several largely complete coronas of Tripneustes (Fig. 6). To our great surprise these contained examples of both T. $g$. gratilla and T. g. elatensis, both of which agreed perfectly in shape and tuberculation with extant material of the respective subspecies.

\section{Discussion}

The main aim of the current study was to clarify the taxonomic status of RS Tripneustes and elucidate its phylogenetic relationships within the genus. Here we employed two independent strategies for species delimitation, a morphological taxonomic approach together with ecological data to outline morpho-species, and molecular phylogenies to assert phylogenetic species. Using both approaches concurrently allowed us to draw robust conclusions and to check for discrepancies between the two. Below we discuss each methodology independently and conclude with a synthesis of both.

\subsection{The taxonomy of RS Tripneustes}

As previously noted by former workers, the high interspecific morphological similarity of Tripneustes renders species delimitation in this genus elusive and most likely incomplete (Clark, 1912; Mortensen, 1928-51). Nonetheless, differences in the gross external appearance between the RS Tripneustes and those from the IWP are pronounced. The compressed test morphology, larger relative diameter of the peristome, reduced number of interambulacral plates and the patchy tuberculation of the aboral interambulacra, manifest significant morphological differences between RS and IWP Tripneustes. These differences were the basis for nominating RS Tripneustes as a sub-species: Tripneustes gratilla elatensis Dafni, 1983. Our findings ratify Dafni's observations and demonstrate additional morphological differences in the distal part of the lantern's compass ossicles and periproct size. These five rodlike ossicles are believed to be involved in a rhythmic upwards and downwards motion that primarily serves as a respiratory pump whose role is to oxygenate the lantern muscles (Wilkie et al., 2015). While in T. gratilla these skeletal elements have a slender, deeply bifurcated structure, in RS Tripneustes they take a flattened robust appearance (Fig. 6). The observed differences might be related to differences in the 
feeding and respiration physiology between the RS and IWP Tripneustes owing to habitat or food preference differences between the two groups of sea urchins. While IWP T. g. gratilla seems to have a strong preference for shallow sandy sea grass beds, RS Tripneustes are more common on rocky and coral covered substrates (Lawrence and Agatsuma, 2013). Our own field observations also demonstrate that while the Zanzibarian Tripneustes sampled in this study did exclusively occur in sea grass meadows, T. g. elatensis, inhabited back reef area, reef flats and lagoons, often perching directly on coral heads (Fig. 6A-C). A recent biodiversity study of the sea grass beds in the Gulf of Aqaba reported a large, $9.7 \mathrm{~km}$ stretch of sea grass beds parallel and adjacent to the coral reef zone (Winters et al., 2015). Very few Tripneustes have been observed during that survey (only two Tripneustes individuals in more than 2,800 data points collected at the northern and southern ends of the sea grass beds; Winters pers. comm.). In contrast, T. g. elatensis was very common along the same stretch of coastline on adjacent reef flats. Although RS Tripneustes have occasionally also been reported occurring on sea grass beds (Dafni and Tobol, 1986; Jafari and Mahasneh, 1987; Nebelsick, 1992), this seems to be the exception rather than the rule. The substantially higher abundance of RS Tripneustes on hard substrate environments (Dafni, 1992; James and Pearse, 1969; Schuhmacher, 1974), despite the spatial proximity of sandy sea grass beds, implies habitat preference.

An important aspect of our morphological dataset is the size range of the individuals used to generate the data. Each of the morphological features we examined was followed and compared between similarly sized individuals ranging from $40 \mathrm{~mm}$ to $80 \mathrm{~mm}$ (Fig. 6). Following the morphological attributes across the entire size range of Tripneustes, allowed us to confirm that the observed differences are not an artifact of ontogeny. Ontogenetic differences, where morphological traits appear, disappear or change over the life course of an individual, may pose a fundamental pitfall in many morphological taxonomic studies (Kroh et al., 2012; Martynov et al., 2015), as exemplified by extreme instances of new genera established by juveniles of other species (e.g., Mooi et al., 2014). A possible solution for this problem is to utilize a wide size range of individuals rather than targeting only the dominant or 'average' size individuals of the studied taxa and to compare specimens of similar size whenever possible.

Inspection of fossil specimens sheds some light on the history of occurrence of the different forms of Tripneustes in the RS. The fossil material clearly demonstrates the occurrence of two forms of Tripneustes, corresponding to the recent $T . g$. 
elatensis and T. g. gratilla, in the RS during the Late Pleistocene (Fig. 6). Except for pedicellariae distribution and compass ossicles that are unaccounted for in the fossil material, all other morphological features demonstrate complete concordance with the recent material. The pronounced compressed test appearance and missing interambulacral tuberculation of one fossil type in contrast to the elevated, completely tuberculated second type is in complete agreement with recent RS and non RS Tripneustes. The presence of these two well-differentiated Tripneustes morphotypes at at-least 120,000 years ago indicates that RS Tripneustes is not a recent offshoot of IWP Tripneustes that formed during the isolation of the RS during the Last Glacial. Instead, it must have evolved well before and presumably survived the Last Glacial hypersaline period in one of the known refugia within the Red Sea Basin (e.g., the Gulf of Aqaba; see DiBattista et al., 2016a), as RS-type Tripneustes are unknown outside the RS, both in modern and fossil faunas. The RS holds 210 echinoderm species, $8.1 \%$ of which are endemic (DiBattista et al., 2016b). Our findings demonstrate that the true extent of RS echinoderm biodiversity and endemism may still be underestimated. The minimum age of the RS Tripneustes clade, however, is in stark conflict with the observed mtDNA data, which show haplotype sharing with as widely distant locations as the Philippines (more than 9,000 km away). A possible explanation for the observed $\mathrm{COI}$ pattern could be complete replacement of RS Tripneustes mtDNA through recent introgression by hybridization with T. g. gratilla. Albeit data on southern RS benthic faunas are scarce and field-work impossible due to the current political situation in the area, there is evidence of a contact zone between T. g. gratilla and T. g. elatensis in the southern-most part of the RS (Fig. 1). Dafni (1983) reported specimens corresponding to $T$. g. gratilla from the Dahlak Archipelago and the Austrian Red Sea Expedition of the vessel "Pola" in 1897/98 collected specimens (NHMW-Zoolll 12639a-d) in nearby "Abajil" (= Jebel Abayil), between Edd and Beylul in Eritrea. Although none of these are suitable for DNAextraction, their morphological characters are fully consistent with IWP Tripneustes and do not at all resemble the depressed RS-form with patchy spines.

\subsection{The phylogeny of Tripneustes}

The present inconclusive taxonomic status of Tripneustes is also reflected by previous molecular studies suggesting that two of the currently recognized species, $T$. gratilla and $T$. depressus, should in fact be treated as a single species (Lessios et al., 2003). This notion was based on both mtDNA (Lessios et al., 2003) and nuDNA 
data (Zigler and Lessios, 2003), and is also reflected in our data, where T. depressus was recovered nesting within or sharing haplotypes within T. gratilla (Fig. 3 and 5). It is clear that an in-depth re-evaluation of the taxonomic status of $T$. depressus is needed to clarify the current morpho-molecular discrepancies that exist in this species, specifically so as there are claims that "a recent global survey of Tripneustes using microsatellite markers revealed that $T$. gratilla can be genetically distinguished from the T. depressus at nuclear loci" (Carlon, pers. comm. in Casilagan et al., 2013).

Similar to previous phylogenetic studies of Tripneustes, our results show strong support for the monophyly of $T$. ventricosus. This notion is confirmed by both mt- and nuDNA data and reflects the morphological and geographic separation of this Atlantic species from the Indo-Pacific Tripneustes species. However, in contrast to earlier phylogenetic reconstructions (Lessios et al., 2003; Zigler and Lessios, 2003), we found well supported genetic clades within T. gratilla. Moreover, although the current study focused on RS Tripneustes, we have examined a large number of $T$. gratilla specimens from various locations throughout their extensive geographic range and also noted several potentially morphologically differentiated populations (Bronstein and Kroh, in prep). Thus, we are compelled to refer to T. gratilla as a species complex rather than a single species. Incorporating new Tripneustes material, preferably from remote and potentially isolated populations throughout the IWP, may shed new light on their evolutionary history and elucidate their true species boundaries.

The RS Tripneustes are presented here in a phylogenetic context for the first time. Our analyses of nuDNA demonstrate their highly supported monophyly (Fig. 5 and S2), which is in line with our morphological taxonomic assessment. T. $g$. elatensis seems to have branched off from $T$. g. gratilla clade $A_{1+2}$ (including $T$. depressus) long before T. ventricosus diverged from the Indo-Pacific stock (ca. 2.83.8 Ma ago). However, these phylogenetic relationships were observed only in the nc (bindin) dataset while the mt data failed to reveal the clustering of $T$. ventricosus with a subset of $T$. g. gratilla (clade $\mathrm{D}_{1+2}$ ), nor did it depict the monophyly of $T$. $g$. elatensis. The mechanisms leading to the observed discrepancies between the $\mathrm{mt}$ and nc markers are discussed below.

\subsection{Mitochondrial and nuclear discordance}


COI sequences analyzed in previous studies (Lessios et al., 2003; Liggins et al., 2014) do not show geographic structure within the IWP Tripneustes (Fig. 4), nor do our new data (Fig. 3), which are based on much longer $\mathrm{COI}$ sequences and for the first time include RS representatives of the genus. The latter group appears polyphyletic based on mtDNA data only. In contrast, phylogenies based on the nc bindin gene produced highly resolved, well supported trees not just between $T$. ventricosus and the rest of Tripneustes, but also between the RS and the other IWP Tripneustes (Figs. 5 and S2). The conflicting results in respect to the RS Tripneustes are intriguing as the phylogenetic resolution of bindin, a nc gene not under positive selection (Zigler and Lessios, 2003), was expected to be lower than that of the $\mathrm{mt}$ $\mathrm{COI}$, as nuclear genes are anticipated to evolve slower (Moore and McPherson, 1965; Palumbi et al., 2001).

\subsection{Unique sequence elements}

The different Tripneustes clades discovered herein show several unique features in their bindin sequences. All of them possess a glycine-rich repeat composed of up to four $30 \mathrm{bp}$ repeat sequences in exon 1. Apart from the RS clade, all Indo-Pacific Tripneustes possess three imperfect repeats. The RS clade shows a fourth repeat, inserted between repeat two and three of Indo-Pacific Tripneustes. T. ventricosus, in contrast, possesses only two repeats (Table S3). These patterns lend independent support to the monophyly of $T$. ventricosus and the RS Tripneustes clade.

Mapping of the transposon discovered in the intron of $T$. g. gratilla, and the unique inverted repeat replacing this transposon in $T$. g. elatensis shows perfect match with the tree topology as recovered by $\mathrm{BI}$ under exclusion of this region (Fig. 5, Table S3), again providing independent support for the relationships among clades, the polyphyly of T. g. gratilla, and the distinctiveness of the RS clade.

\subsection{Conclusions}

Based on the evidence put forward above, we can confirm Dafni's (1983) conclusions that the northern RS population of Tripneustes is a distinct taxon from IWP Tripneustes. It A) can be straightforwardly differentiated morphologically, both in the field and in preserved specimens, B) represents a distinct genetic clade, C) exists as morphologically well-differentiated form already in the Late Pleistocene (fossil 
evidence), D) has diverged from other Tripneustes clades more than 2 million years ago (based on the molecular clock analysis presented above), and E) show different habitat preference than IWP Tripneustes. Dafni, therefore, was correct to establish a novel taxon for the northern RS population of Tripneustes - T. gratilla elatensis. While the morphological data show that it is very different from IWP T. g. gratilla and possible is, in fact, a distinct species, we currently lack sufficient molecular data to judge if the differentiation seen in bindin is reflected in other nuclear markers as well.

We assume that recent $\mathrm{mt}$ introgression due to hybridization in the contact zone between RS T. g. elatensis and T. g. gratilla is the most parsimonious explanation for the $\mathrm{mt} / \mathrm{nc}$ discordance observed. In addition, disconnection of the RS from the Gulf of Aden during the Pleistocene may have temporarily separated these two clades, promoting speciation. Similar introgression must have happened (or might still be ongoing) between members of the sympatric $T$. g. gratilla clades identified by bindin data. For these, more detailed studies involving additional loci, material from the complete range of $T$. g. gratilla and specimens of different ontogenetic stages will be necessary to resolve their true distribution, relationship and morphological distinction (if any). This in turn could provide fundamental insights onto the evolutionary history of this genus and advance our understanding of marine speciation.

\section{Acknowledgements}

We wish to thank Rich Mooi and Christina Piotrowski (California Academy of Sciences), Gustav Paulay (Florida Museum of Natural History), Emmanuel Antig (Cebu City), Baraka Kuguru (Tanzania Fisheries Research Institute) for facilitating access to specimens and Heidi Friedhoff for loan and donation of fossil Tripneustes specimens. Josef Harl (NHM Vienna) as well as Tamar Feldstein and Michal HadasSason (SMNH, Tel Aviv University) are acknowledged for assistance in the laboratory and discussion of results. We particularly want to thank Barbara Däubl (NHM Vienna) for her help in adapting the molecular protocols to Tripneustes and continuous support during laboratory work. We gratefully acknowledge Harilaos Lessios (Smithsonian Tropical Research Institute) for providing assistance during the early stages of the study, and the National Natural History Collections at the Hebrew University of Jerusalem for providing access to their collections.

We gratefully acknowledge the Department of Agriculture of the Philippines, particularly the Bureau of Fisheries and Aquatic Resources (BFAR) and the National 
Fisheries Research and Development Institute (NFDRI) for support of the 2014-2016 Verde Island Passage Expeditions of the California Academy of Sciences (CAS). Tissue samples used herein were collected by Rich Mooi (CAS) under funding from NSF grant 12-57630 "Collaborative Proposal: Documenting Diversity in the Apex of the Coral Triangle: Inventory of Philippine Marine Biodiversity".

Finally we thank Gustav Paulay and an anonymous reviewer for their constructive comments that helped to improve the manuscript.

This research received support from the SYNTHESYS Project (http://www.synthesys.info/), which is financed by European Community Research Infrastructure Action under the FP7 "Capacities" Programme. 


\section{References}

Amato, K.R., Emel, S.L., Lindgren, C.A., Sullan, K.M., Wright, P.R., Gilbert, J.J., 2008. Covering behavior of two co-occurring Jamaican sea urchins: differences in the amount of covering and selection of covering material. Bulletin of Marine Science 82, 255-261.

Avise, J.C., 1994. Molecular Markers, Natural History and Evolution. Chapman and Hall, New York.

Avise, J.C., 2000. Phylogeography: the history and formation of species. Harvard Univ. Press, Cambridge, MA.

Bacon, C.D., Silvestro, D., Jaramillo, C., Smith, B.T., Chakrabarty, P., Antonelli, A., 2015a. Biological evidence supports an early and complex emergence of the Isthmus of Panama. Proceedings of the National Academy of Sciences 112, 6110-6115.

Bacon, C.D., Silvestro, D., Jaramillo, C., Smith, B.T., Chakrabarty, P., Antonelli, A., 2015b. Reply to Lessios and Marko et al.: Early and progressive migration across the Isthmus of Panama is robust to missing data and biases. Proceedings of the National Academy of Sciences 112, E5767-E5768.Bailey, G., 2009. The Red Sea, coastal landscapes, and hominin dispersals. In: Petraglia, M.D., Rose, J.L. (Eds.), The evolution of human populations in Arabia. Springer, Dordrecht, Netherlands, pp. 15-37.

Bailey, G.N., Flemming, N.C., King, G.C.P., Lambeck, K., Momber, G., Moran, L.J., Al-Sharekh, A., Vita-Finzi, C., 2007. Coastlines, submerged landscapes, and human evolution: The Red Sea basin and the Farasan Islands. The Journal of Island and Coastal Archaeology 2, 127-160.

Bao, W., Jurka, J., 2008. DNA transposons from Strongylocentrotus purpuratus. Repbase Reports 8, 2109-2109.

Bongrain, M., 2013. Les accumulations de Gigantopecten restitutensis (Fontannes, 1884) (Mollusca: Bivalvia: Pectinidae) dans le Burdigalien supérieur des carrières de Ménerbes et de Lacoste (Vaucluse, bassin d'Apt, SE France): analyse et hypothèse explicative. Geodiversitas 35, 607-628.

Bowen, B.W., Rocha, L.A., Toonen, R.J., Karl, S.A., 2013. The origins of tropical marine biodiversity. Trends in Ecology and Evolution 28, 359-366.

Capella-Gutiérrez, S., Silla-Martínez, J.M., Gabaldón, T., 2009. trimAl: a tool for automated alignment trimming in large-scale phylogenetic analyses. Bioinformatics 25, 1972-1973. 
Casilagan, I.L.N., Juinio-Meñez, M.A., Crandall, E.D., 2013. Genetic diversity, population structure, and demographic history of exploited sea urchin populations (Tripneustes gratilla) in the Philippines. Journal of Experimental Marine Biology and Ecology 449, 284-293.

Chen, C.-P., Chang, K.-H., 1981. Reproductive periodicity of the sea urchin, Tripneustes gratilla (L.) in Taiwan compared with other regions. International Journal of Invertebrate Reproduction 3, 309-319.

Clark, H.L., 1912. Hawaiian and other Pacific Echini. Memoirs of the Museum of Comparative Zoology 34, 205.

Coates, A.G., Obando, J.A., 1996. The geologic evolution of the Central American Isthmus. In: Jackson, J.B.C., Coates, A.G., Budd, A. (Eds.), Evolution and Environment in Tropical America. University of Chicago Press, Chicago, IL, pp. 21-56.

Coates, A.G., Aubry, M.P., Berggren, W.A., Collins, L.S., Kunk, M., 2003. Early Neogene history of the Central American arc from Bocas del Toro, western Panama. Geological Society of America Bulletin 115, 271-287.

Coppard, S.E., Zigler, K.S., Lessios, H.A., 2013. Phylogeography of the sand dollar genus Mellita: Cryptic speciation along the coasts of the Americas. Molecular Phylogenetics and Evolution 69, 1033-1042.

Currie, R.I., Fisher, A.E., Hargreaves, P.M., 1973. Arabian Sea upwelling. In: Zeitzschel, B., Gerlach, S. (Eds.), The Biology of the Indian Ocean. Springer Berlin Heidelberg, pp. 37-52.

Dafni, J., 1983. A new subspecies of Tripneustes gratilla from the northern Red Sea (Echinodermata: Echinoidea: Toxopneustidae). Israel Journal of Zoology 32, 112.

Dafni, J., 1992. Growth rate of the sea urchin Tripneustes gratilla elatensis. Israel Journal of Zoology 38, 25-33.

Dafni, J., Tobol, R., 1986. Population structure patterns of a common Red Sea echinoid (Tripneustes gratilla elatensis). Israel Journal of Zoology 34, 191-204.

DiBattista, J.D., Berumen, M.L., Gaither, M.R., Rocha, L.A., Eble, J.A., Choat, J.H., Craig, M.T., Skillings, D.J., Bowen, B.W., 2013. After continents divide: comparative phylogeography of reef fishes from the Red Sea and Indian Ocean. Journal of Biogeography 40, 1170-1181.

DiBattista, J.D., Choat, J.H., Gaither, M.R., Hobbs, J.-P.A., Lozano-Cortés, D.F., Myers, R.F., Paulay, G., Rocha, L.A., Toonen, R.J., Westneat, M.W., Berumen, M.L., 2016a. On the origin of endemic species in the Red Sea. Journal of Biogeography 43, 13-30. 
DiBattista, J.D., Roberts, M.B., Bouwmeester, J., Bowen, B.W., Coker, D.J., LozanoCortés, D.F., Choat, J.H., Gaither, M.R., Hobbs, J.-P.A., Khalil, M.T., Kochzius, M., Myers, R.F., Paulay, G., Robitzch, V.S.N., Saenz-Agudelo, P., Salas, E., Sinclair-Taylor, T.H., Toonen, R.J., Westneat, M.W., Williams, S.T., Berumen, M.L., 2016b. A review of contemporary patterns of endemism for shallow water reef fauna in the Red Sea. Journal of Biogeography 43, 423-439.

Dollfus, R., Roman, J., 1981. Les échinides de la Mer Rouge, Monographie zoologique et paléontologique. Ministère des Universités, Comité des Travaux Historiques et Scientifiques, Mémoires de la Section des Sciences 9, 1-145.

Doyle, J.J., 1997. Trees within trees: genes and species, molecules and morphology. Systematic Biology 46, 537-553.

Drummond, A.J., Rambaut, A., 2007. BEAST: Bayesian evolutionary analysis by sampling trees. BMC Evolutionary Biology 7, 1-8.

Fenton, M., Geiselhart, S., Rohling, E.J., Hemleben, C., 2000. Aplanktonic zones in the Red Sea. Marine Micropaleontology 40, 277-294.

Funk, D.J., Omland, K.E., 2003. Species-level paraphyly and polyphyly: frequency, causes, and consequences, with Insights from animal mitochondrial DNA. Annual Review of Ecology, Evolution, and Systematics 34, 397-423.

Gernhard, T., 2008. The conditioned reconstructed process. Journal of Theoretical Biology 253, 769-778.

Gordon, C.M., Donovan, S.K. 1992. Disarticulated echinoid ossicles in paleoecology and taphonomy: the last interglacial Falmouth Formation of Jamaica. Palaios 7, 157-166.

Greenstein, B.J., 1991. An integrated study of echinoid taphonomy: Predictions for the fossil record of four echinoid families. Palaios 6, 519-540.

Greenstein, B.J., 1993. Is the fossil record of regular echinoids really so poor? A Comparison of living and subfossil assemblages. Palaios 8, 587-601.

Hall, T.A., 1999. BioEdit: a user-friendly biological sequence alignment editor and analysis program for Windows 95/98/NT. Nucleic Acids Symposium Series 41, 95-98.

Jacobs, H.T., Elliott, D.J., Math, V.B., Farquharson, A., 1988. Nucleotide sequence and gene organization of sea urchin mitochondrial DNA. Journal of Molecular Biology 202, 185-217.

Jafari, R.D., Mahasneh, D.M., 1987. The effect of seagrass grazing on the sexual maturity of title sea urchin Tripneustes gratilla In the Gulf of Aqaba (Jordan). Dirasat 14, 127-136. 
James, D.B., Pearse, J.S., 1969. Echinoderms from the Gulf of Suez and the Northern Red Sea. Biological Association of India 11, 78-125.

Kehas, A.J., Theoharides, K.A., Gilbert, J.J., 2005. Effect of sunlight intensity and albinism on the covering response of the Caribbean sea urchin Tripneustes ventricosus. Marine Biology 146, 1111-1117.

Kemp, J.M., 1998. Zoogeography of the coral reef fishes of the Socotra Archipelago. Journal of Biogeography 25, 919-933.

Kemp, J.M., 2000. Zoogeography of the coral reef fishes of the north-eastern Gulf of Aden, with eight new records of coral reef fishes from Arabia. Fauna of Arabia 18, 293-321.

Kier, P.M. 1977. The poor fossil record of the regular echinoid. Paleobiology 3, 168174.

Kimura, M., 1980. A simple method for estimating evolutionary rates of base substitutions through comparative studies of nucleotide sequences. Journal of Molecular Evolution 16, 111-120.

Kinsman, D.J.J., 1964. Reef coral tolerance of high temperatures and salinities. Nature 202, 1280-1282.

Kohany, O., Gentles, A.J., Hankus, L., Jurka, J., 2006. Annotation, submission and screening of repetitive elements in Repbase: RepbaseSubmitter and Censor. BMC Bioinformatics 7, 474-474.

Kroh, A., Madeira, P., Haring, E., 2012. Species distributions: virtual or real - the case of Arbaciella elegans (Echinoidea: Arbaciidae). Journal of Zoological Systematics and Evolutionary Research 50, 99-105.

Lanfear, R., Calcott, B., Ho, S.Y.W., Guindon, S., 2012. PartitionFinder: Combined Selection of Partitioning Schemes and Substitution Models for Phylogenetic Analyses. Molecular Biology and Evolution 29, 1695-1701.

Larkin, M.A., Blackshields, G., Brown, N.P., Chenna, R., McGettigan, P.A., McWilliam, H., Valentin, F., Wallace, I.M., Wilm, A., Lopez, R., 2007. Clustal W and Clustal X version 2.0. Bioinformatics 23, 2947-2948.

Lawrence, J.M., Agatsuma, Y., 2013. Tripneustes. In: Lawrence, J.M. (Ed.), Sea Urchins: Biology and Ecology. Elsevier, pp. 491-507.

Leaché, A.D., McGuire, J.A., 2006. Phylogenetic relationships of horned lizards (Phrynosoma) based on nuclear and mitochondrial data: Evidence for a misleading mitochondrial gene tree. Molecular Phylogenetics and Evolution 39, 628-644.

Lee, T. (2011). A systematic study of Korean echinoids based on morphology and molecular phylogeny, Sahmyook University. 
Leigh, J.W., Bryant, D., 2015. Popart: full-feature software for haplotype network construction. Methods in Ecology and Evolution 6, 1110-1116.

Lessios, H.A., 2015. Appearance of an early closure of the Isthmus of Panama is the product of biased inclusion of data in the metaanalysis. Proceedings of the National Academy of Sciences 112, E5765.

Lessios, H.A., Kane, J., Robertson, D.R., 2003. Phylogeography of the pantropical sea urchin Tripneustes: contrasting patterns of population structure between oceans. Evolution 57, 2026-2036.

Lessios, H.A., Lockhart, S., Collin, R., Sotil, G., Sanchez-Jerez, P., Zigler, K.S., Perez, A.F., Garrido, M.J., Geyer, L.B., Bernardi, G., Vaquier, V.D., Haroun, R., Kessing, B.D. 2012. Phylogeography and bindin evolution in Arbacia, a sea urchin genus with an unusual distribution. Molecular Ecology 21, 130-144.

Liggins, L., Gleeson, L., Riginos, C., 2014. Evaluating edge-of-range genetic patterns for tropical echinoderms, Acanthaster planci and Tripneustes gratilla, of the Kermadec Islands, southwest Pacific. Bulletin of Marine Science 90, 379-397.

Ludt, W.B., Rocha, L.A., 2015. Shifting seas: the impacts of Pleistocene sea-level fluctuations on the evolution of tropical marine taxa. Journal of Biogeography 42, 25-38.

Maddison, W.P., 1997. Gene trees in species trees. Systematic Biology 46, 523-536.

Malay, M.C.D., Paulay, G., 2010. Peripatric speciation drives diversification and distributional pattern of reef hermit crabs (Decapoda: Diogenidae: Calcinus). Evolution 64, 634-662.

Mansour, A.M., Madkour, H.A., 2015. Raised Coral Reefs and Sediments in the Coastal Area of the Red Sea. In: Rasul, N.M.A., Stewart, I.C.F. (Eds.), The Red Sea. Springer-Verlag Berlin Heidelberg, pp. 379-393.

Marko, P.B., Eytan, R.I., Knowlton, N., 2015. Do large molecular sequence divergences imply an early closure of the Isthmus of Panama? Proceedings of the National Academy of Sciences 112, E5766

Martynov, A., Ishida, Y., Irimura, S., Tajiri, R., O'Hara, T., Fujita, T., 2015. When ontogeny matters: A new Japanese species of brittle star illustrates the importance of considering both adult and juvenile characters in taxonomic practice. PLoS ONE 10, e0139463.

Mayr, E., 1954. Geographic speciation in tropical echinoids. Evolution 8, 1-18.

McCartney, M.A., Keller, G., Lessios, H.A., 2000. Dispersal barriers in tropical oceans and speciation in Atlantic and eastern Pacific sea urchins of the genus Echinometra. Molecular Ecology 9, 1391-1400. 
McGuire, J.A., Linkem, C.W., Koo, M.S., Hutchison, D.W., Lappin, A.K., Orange, D.I., Lemos-Espinal, J., Riddle, B.R., Jaeger, J.R., 2007. Mitochondrial introgression and incomplete lineage sorting through space and time: phylogenetics of crotaphytid lizards. Evolution 61, 2879-2897.

McPherson, B.F., 1965. Contributions to the biology of the sea urchin Tripneustes Ventricosus. Bulletin of Marine Science 15, 228-244.

Metz, E.C., Palumbi, S.R., 1996. Positive selection and sequence rearrangements generate extensive polymorphism in the gamete recognition protein bindin. Molecular Biology and Evolution 13, 397-406.

Mooi, R., Kroh, A., Srivastava, D.K., 2014. Phylogenetic re-evaluation of fossil and extant micro-echinoids with revision of Tridium, Cyamidia, and Lenicyamidia (Echinoidea: Clypeasteroida). Zootaxa 3857, 501-526.

Moore, H.B., McPherson, B.F., 1965. A contribution to the study of the productivity of the urchins Tripneustes esculentus and Lytechinus variegatus. Bulletin of Marine Science 15, 855-871.

Mortensen, T.H., 1928-51. A monograph of the Echinoidea. C. A. Reitzel, Copenhagen.

Mos, B., Cowden, K.L., Dworjanyn, S.A., 2012. Potential for the commercial culture of the tropical sea urchin Tripneustes gratilla in Australia.

Muthiga, N.A., 2005. Testing for the effects of seasonal and lunar periodicity on the reproduction of the edible sea urchin Tripneustes gratilla $(L)$ in Kenyan coral reef lagoons. Hydrobiologia 549, 57-64.

Nebelsick, J.H., 1992. The northern bay of Safaga (Red Sea, Egypt): An actuopalaeontological approach III. Distribution of echinoids. Beiträge zur Paläontologie von Österreich 17, 5-79.

Nichols, R., 2001. Gene trees and species trees are not the same. Trends in Ecology and Evolution 16, 358-364.

Palumbi, S.R., 1994. Genetic divergence, reproductive isolation, and marine speciation. Annual Review of Ecology and Systematics 25, 547-572.

Palumbi, S.R., 1996. What can molecular genetics contribute to marine biogeography? An urchin's tale. Journal of Experimental Marine Biology and Ecology 203, 75-92.

Palumbi, S.R., Cipriano, F., Hare, M.P., 2001. Predicting nuclear gene coalescence from mitochondrial data: The Three-Times rule. Evolution 55, 859-868.

Pearse, J.S., 1974. Reproductive patterns of tropical reef animals: three species of sea urchins. In: Cameron, A.M., Cambell, B.M., Cribb, A.B., Endean, R., Jell, J.S., Jones, O.A., Mather, P., Talbot, F.H. (Eds.), Proceedings of the Second 
International Coral Reef Symposium. The Great Barrier Reef Committee, Brisbane, Australia, pp. 235-240.

Por, F.D., 1972. Hydrobiological notes on high-salinity waters of Sinai Peninsula. Marine Biology 14, 111-119.

Por, F.D., 2008. Life beyond 41 ppm. Metahaline environments and anchialine pools in the Gulf of Aqaba-Eilat. In: Por, F.D. (Ed.), Aqaba-Eilat, the improbable Gulf: environment, biodiversity and protection. Magnes Press, Jerusalem, pp. 135152.

Ragaini, L., 1997. Echinoid fauna from the Quaternary fringing reef of Aqaba (Jordan). Palaeontographia Italica 84, 1-19.

Rambaut, A., Drummond, A.J., Suchard, M., 2013. Tracer v1.6.

Reuter, J.S., Mathews, D.H., 2010. RNAstructure: software for RNA secondary structure prediction and analysis. BMC Bioinformatics 11, 129-129.

Rohling, E.J., Grant, K., Bolshaw, M., Roberts, A.P., Siddall, M., Hemleben, C., Kucera, M., 2009. Antarctic temperature and global sea level closely coupled over the past five glacial cycles. Nature Geoscience 2, 500-504.

Ronquist, F., Huelsenbeck, J.P., 2003. MrBayes 3: Bayesian phylogenetic inference under mixed models. Bioinformatics 19, 1572-1574.

Ruedi, M., Smith, M.F., Patton, J.L., 1997. Phylogenetic evidence of mitochondrial DNA introgression among pocket gophers in New Mexico (family Geomyidae). Molecular Ecology 6, 453-462.

Schuhmacher, H., 1974. On the conditions accompanying the first settlement of coral on artificial reef with special reference to the influence of grazing sea urchin (Eilat, Red Sea). In: Cameron, A.M., Cambell, B.M., Cribb, A.B., Endean, R., Jell, J.S., Jones, O.A., Mather, P., Talbot, F.H. (Ed.), Proceedings of the Second International Coral Reef Symposium. The Great Barrier Reef Committee, Brisbane, Australia, pp. 257-268.

Schwarz, S., 1978. Estimating the dimension of a model. The Annals of Statistics 6, 461-464.

Siddall, M., Rohling, E.J., Almogi-Labin, A., Hemleben, C., Meischner, D., Schmelzer, I., Smeed, D.A., 2003. Sea-level fluctuations during the last glacial cycle. Nature 423, 853-858.

Skillings, D.J., Bird, C.E., Toonen, R.J., 2011. Gateways to Hawai'i: genetic population structure of the tropical sea cucumber Holothuria atra. Journal of Marine Biology 2011, 16.

Smeed, D., 1997. Seasonal variation of the flow in the strait of Bab al Mandab. Oceanologica Acta 20, 773-781. 
Smith, A.B., Kroh, A., 2013. Phylogeny of sea urchins. In: Lawrence, J.M. (Ed.), Sea Urchins: Biology and Ecology. Elsevier, pp. 1-14.

Stamatakis, A., 2006. RAxML-VI-HPC: maximum likelihood-based phylogenetic analyses with thousands of taxa and mixed models. Bioinformatics 22, 26882690.

Tamura, K., Stecher, G., Peterson, D., Filipski, A., Kumar, S., 2013. MEGA6: Molecular Evolutionary Genetics Analysis Version 6.0. Molecular Biology and Evolution 30, 2725-2729.

Thunell, R.C., Locke, S.M., Williams, D.F., 1988. Glacio-eustatic sea-level control on Red-Sea salinity. Nature 334, 601-604.

Toha, A.H.A., Sumitro, S.B., Widodo, Hakim, L., 2015. Color diversity and distribution of sea urchin Tripneustes gratilla in Cenderawasih Bay ecoregion of Papua, Indonesia. The Egyptian Journal of Aquatic Research 41, 273-278.

Vaïtilingon, D., Rasolofonirina, R., Jangoux, M., 2005. Reproductive cycle of edible echinoderms from the southwestern Indian Ocean I. Tripneustes gratilla L. (Echinoidea, Echinodermata). Western Indian Ocean Journal of Marine Science 4, 47-60.

Valverde, J.R., Marco, R., Garesse, R., 1994. A conserved heptamer motif for ribosomal RNA transcription termination in animal mitochondria. Proceedings of the National Academy of Sciences of the United States of America 91, 53685371.

Vonk, J.A., Pijnappels, M.H.J., Stapel, J., 2008. In situ quantification of Tripneustes gratilla grazing and its effects on three co-occurring tropical seagrass species. Marine Ecology Progress Series 360, 107-114.

Wilkie, I.C., Fassini, D., Cullorà, E., Barbaglio, A., Tricarico, S., Sugni, M., Del Giacco, L., Candia Carnevali, M.D., 2015. Mechanical properties of the compass depressors of the sea-urchin Paracentrotus lividus (Echinodermata, Echinoidea) and the effects of enzymes, neurotransmitters and synthetic tensilin-like protein. PLoS ONE 10, e0120339.

Winters, G., Shem-Tov, R., Elmaliach, T., Edelist, D., Rilov, G., 2015. Assessment of seagrass communities in the northern Gulf of Aqaba: 1. mapping their distribution. PeerJ 1175v1171.

Xia, X., 2013. DAMBE5: A comprehensive software package for data analysis in molecular biology and evolution. Molecular Biology and Evolution 30, 1720-1728.

Zigler, K.S., Lessios, H.A., 2003. Evolution of bindin in the pantropical sea urchin Tripneustes: comparisons to bindin of other genera. Molecular Biology and Evolution 20, 220-231. 
Zigler, K.S., Lessios, H.A., 2004. Speciation on the coasts of the new world: phylogeography and the evolution of bindin in the sea urchin genus Lytechinus. Evolution 58, 1225-1241. 
Figure Captions

Fig. 1. Maps of the Red Sea and Indian Ocean indicating distribution (according to Mortensen, 1943) and sample collection localities of Tripneustes. Colored areas indicate species ranges being green for Tripneustes g. gratilla and red for Tripneustes elatensis. Stars indicate sampling sites of the current study. Red and open circles indicate confirmed occurrences of recent and fossil T. g. elatensis in the Red Sea, respectively. Green and open triangles indicate confirmed occurrences of recent and fossil T. g. gratilla in the Red Sea, respectively. The maps were compiled based on data generated in the current study and the data obtained from: Dollfus and Roman (1981), Dafni (1983), Ragaini (1997), and specimens deposited at The Steinhardt Museum of Natural History, Tel-Aviv, Israel and specimens collected during the "Pola" Red Sea expedition (deposited at the Natural History Museum, Vienna, Austria).

Fig. 2. Schematic illustrations of gene regions and primer binding sites of the mitochondrial cytochrome c oxidase subunit 1 gene $(\mathrm{CO})(\mathrm{A})$, and the nuclear bindin gene $(\mathrm{B})$, used in the current study. The $\mathrm{COI}$ fragments generated in the current study are illustrated alongside the PCR fragments generated by Lessios et al. (2003) and Liggins et al. (2014). Position of the exons and the intron is outlined for the bindin gene. Corresponding fragment lengths are indicated in parentheses.

Fig. 3. Phylogenetic BI tree of 531 bp long Tripneustes $\mathrm{COI}$ sequences. The tree reconstruction is based on 33 unique haplotypes representing the three extant species of Tripneustes and the RS T. g. elatensis; rooted on Lytechinus variegatus. Supporting values (> 0.9 posterior probabilities and $>50 \% \mathrm{ML}$ bootstrap values) are shown above the nodes. The colors of the specimen labels correspond to: Dark green - T. g. gratilla, Red - T. g. elatensis, Light green - T. depressus, and Blue - T. ventricosus. Clades 1-5 are discussed in the text. Details on the sequences used for this tree are given in Table S2.

Fig. 4. Median-joining haplotype network with $\mathrm{COI}$ sequences of Tripneustes. The network comprises 328 sequences, 449 bp long, of sequences generated in the current study and most comparable Tripneustes $\mathrm{CO}$ sequences in the literature (for details see Table S2). Color code as in Fig. 3. Bars indicate the number of substitutions between nodes. The frequency of each haplotype is indicated by size (see key, bottom left).

Fig. 5. Phylogenetic BI tree of 1226 bp long Tripneustes bindin sequences including exons 1 (without glycine-rich repeat) and 2 and parts of the intron (see Fig. 2; bin- 
compl dataset). The tree reconstruction is based on 42 unique haplotypes representing the three extant species of Tripneustes and the RS T. g. elatensis; applying midpoint rooting. Supporting values ( $>0.9$ posterior probabilities and $>50 \%$ ML bootstrap values) are shown above the nodes. Color code as in Fig. 3. Clades A$E$ are discussed in the text. Details on the sequences used for this tree are given in Table S2.

Fig. 6. Morphological features of Tripneustes g. elatensis in comparison with $T . g$. gratilla. A-D: Life images of T. g. elatensis color morphs (A-C: El Quesir, Egypt) in comparison to T. g. gratilla (D: Luzon, Philippines; specimen CASIZ 187156). E-F: Fossil Tripneustes specimens from Late Pleistocene raised reef terraces in Egypt (MIS 5e, ca. 120,000 yrs old); E: T. g. elatensis, El Quesir, Egypt, NHMW 2013/0280/0012; F: T. g. gratilla, Hurghada, Egypt, NHMW 2016/0013/0001). G-H: Distribution of primary tubercles in the aboral interambulacra of Tripneustes (G: T. g. elatensis, specimen NHMW 2016/0012/0003; B: T. g. gratilla, specimen ZnTg100). I$\mathrm{P}$ : Comparison of distal compass shape at different specimen sizes; this a part of the Aristotle's lantern, which is much more robust in T. g. elatensis $\{\mathrm{I}-\mathrm{L}:$ T. g. gratilla [I: $40.8 \mathrm{~mm}$ test diameter (TD), Cebu, Philippines, NHMW 2014/0208/0001; J: $48.2 \mathrm{~mm}$ TD, Cebu, Philippines, NHMW 2014/0208/0004; K: 63.1 mm TD, Cebu, Philippines, NHMW 2016/0025/0007; L: 71.38 mm TD, Cebu, Philippines, NHMW 2012/0193/0006]; M-P: T. g. elatensis [M: $45.1 \mathrm{~mm}$ TD, Aqaba, Jordan, NHMW 2016/0012/0001; N: 49.3 mm TD, Eilat, Israel, NHMW 2016/0012/0004; O: 63.5 mm TD, Aqaba, Jordan, NHMW 2016/0012/0002; P: 71.4 mm TD, Aqaba, Jordan, NHMW 2016/0012/0003]\}. 


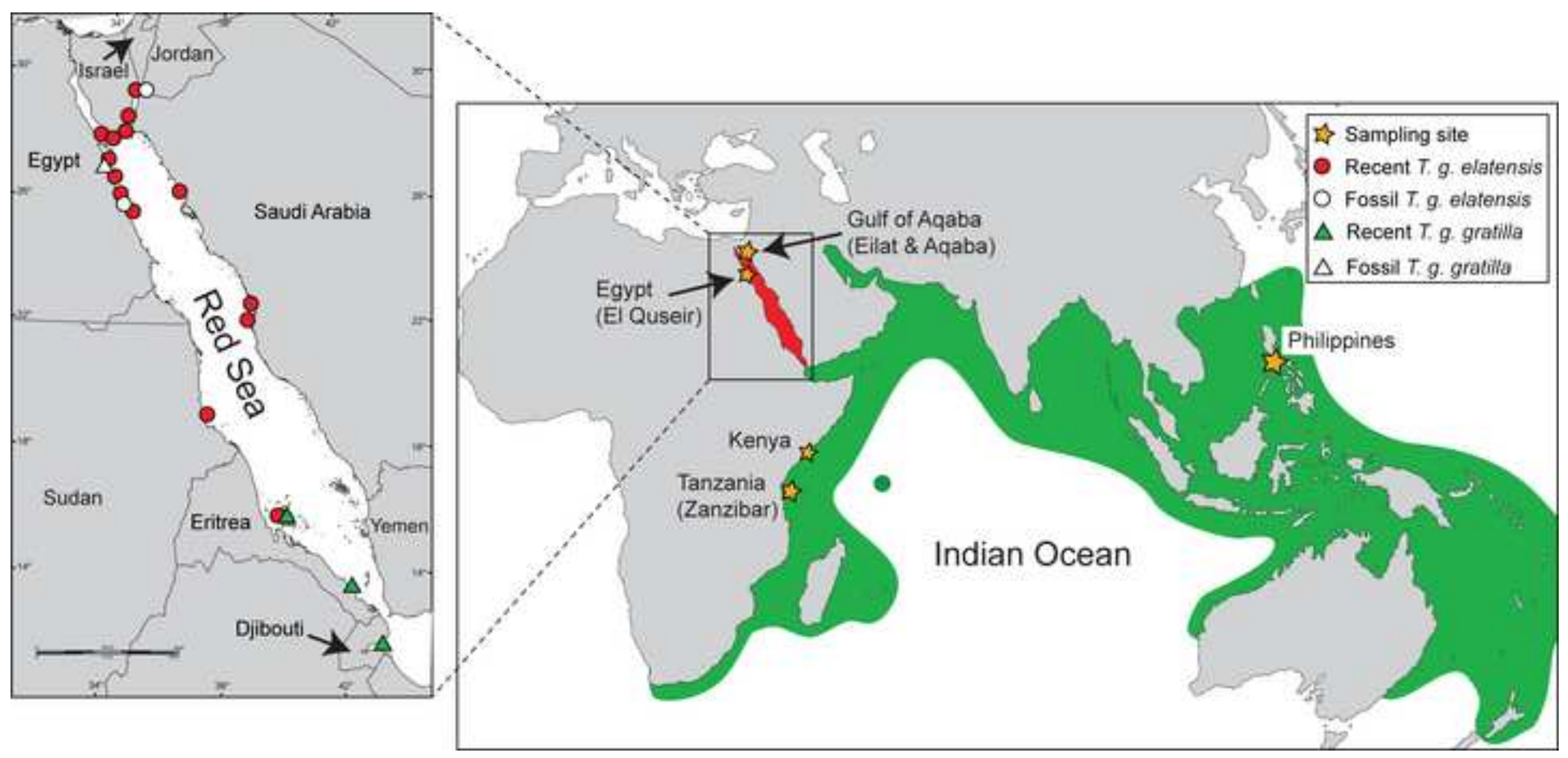


(A) Cytochrome $c$ oxidase (COI)

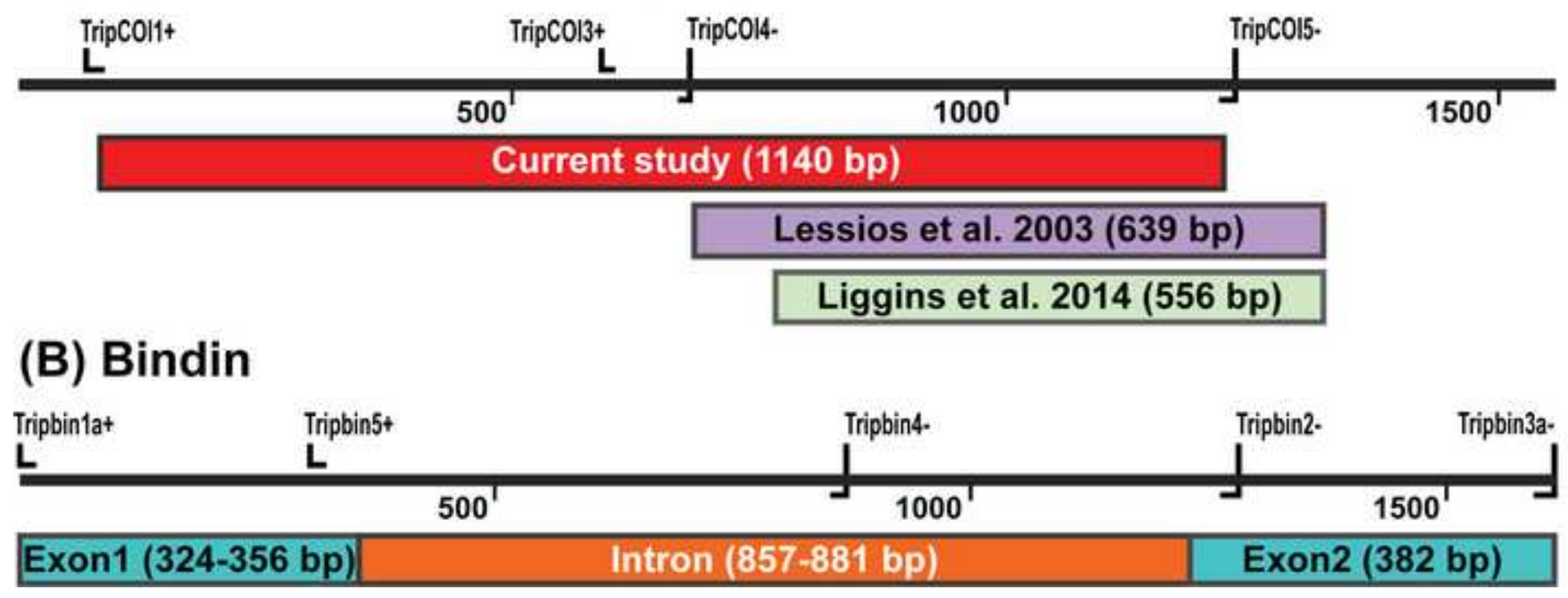

(B) Bindin

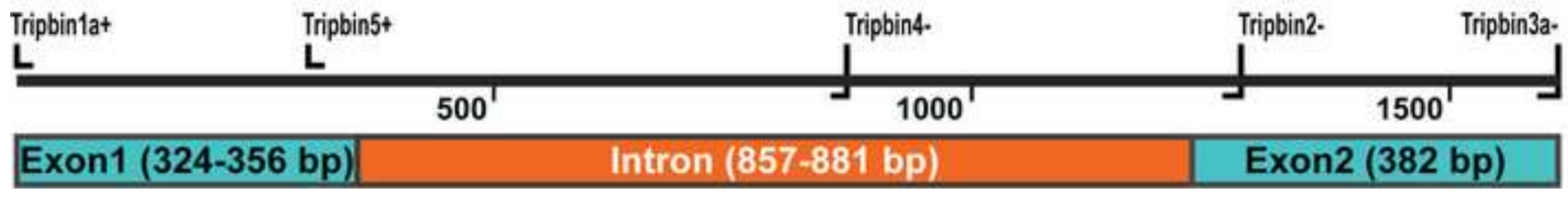


Tripneustes COI 531bp

Bayesian inference tree

Nucleotide substitution model:

$\mathrm{HKY}+\mathrm{I}$

$0.86 / 56$ - RSEQ1_RS3.1_RSJo1_RS4,2_RS6.2_RS10.1_RSEQ2_PI7.0_Pi8.0 :3

- Pi187156K_Pi187157.2_Pi187187

L ZnTg104

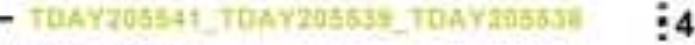

$-\mathrm{TG} \times \mathbf{5} 661146$

- TGAY205425_TGAY205424

- TGAY205441_TGJO341159

- Pi137157.1

TGAY205392_TGJX661157_TGJX661188_TGAY205396

TGAY205385 TGAY205402 TGAY205399 Pi187147 PH1B7157.3

- TOAY205412_Pi187193

- $2 n \operatorname{Tg} 103$

- RSEIT

- RSB.2

$0.68 \%$ -

- RSEQ18

[ RSE12_RS7_RS8,3_RSJo1d_RSJo2_RSJo2d_RS4,1_RS6,1_RS10.2_RSEQ7_RSEQ19_RSEQ20 :

1186

157

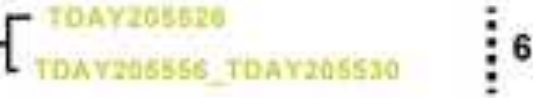

TGAY 205408

LTGAY205419_TGAY205420

TGAY205374_TGAY205445

- $\mathrm{ZnTg} 100$

- ZnTg101

- $\mathrm{ZnTg} 102$

- KenTrip1

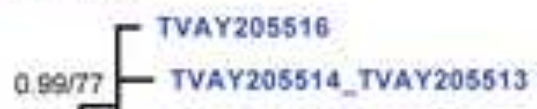

$0.90 / 79$

- TVAY205495_TVAY205494_TVAY205493_TVAY205492_TVAY205409

L TVAY205497_TVAY205498 

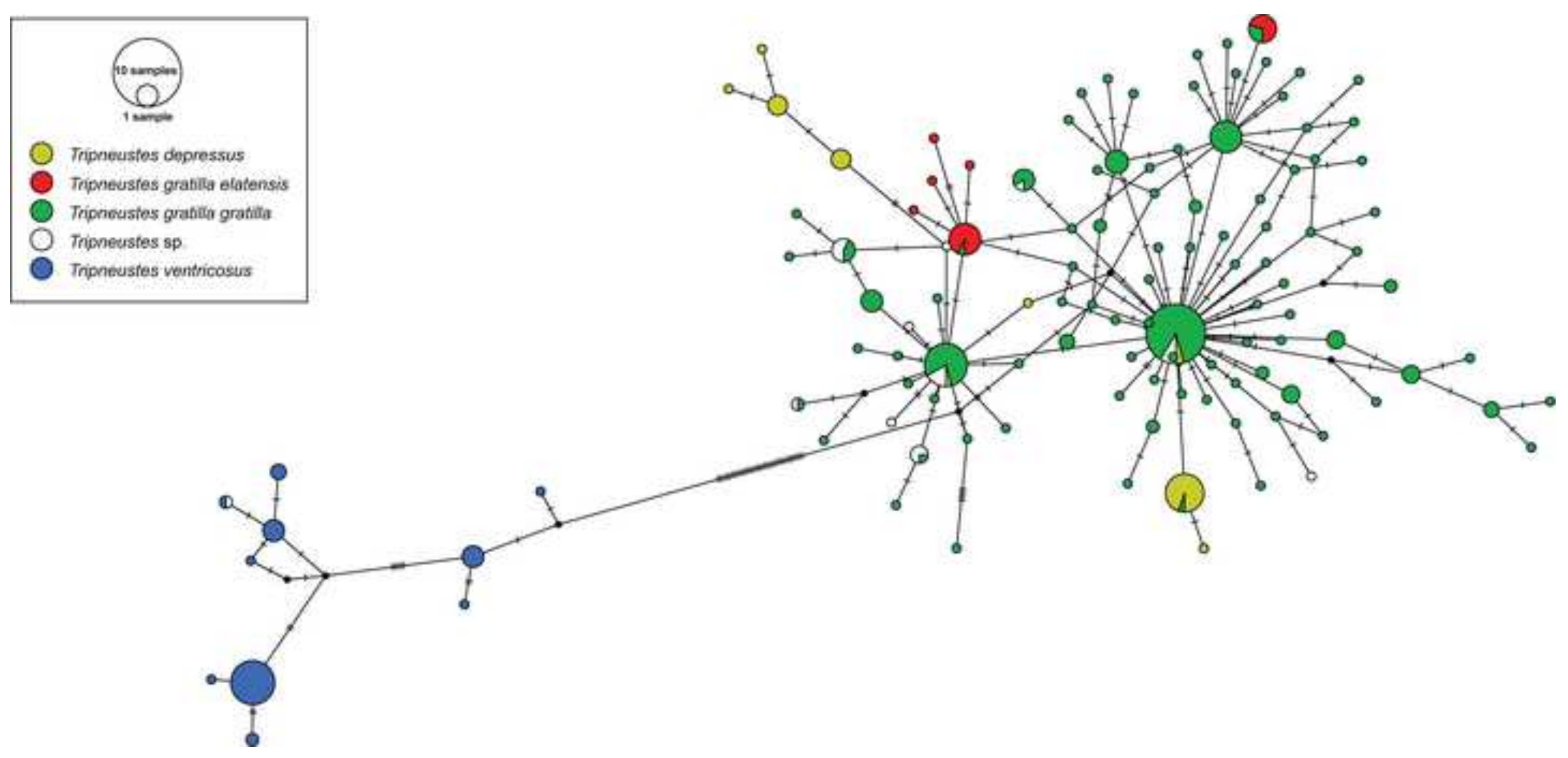
Tripneustes bindin exons + intron

Bayesian inference tree

Nucleotide substitution model:

$\mathrm{HKY}+\mathrm{G}$

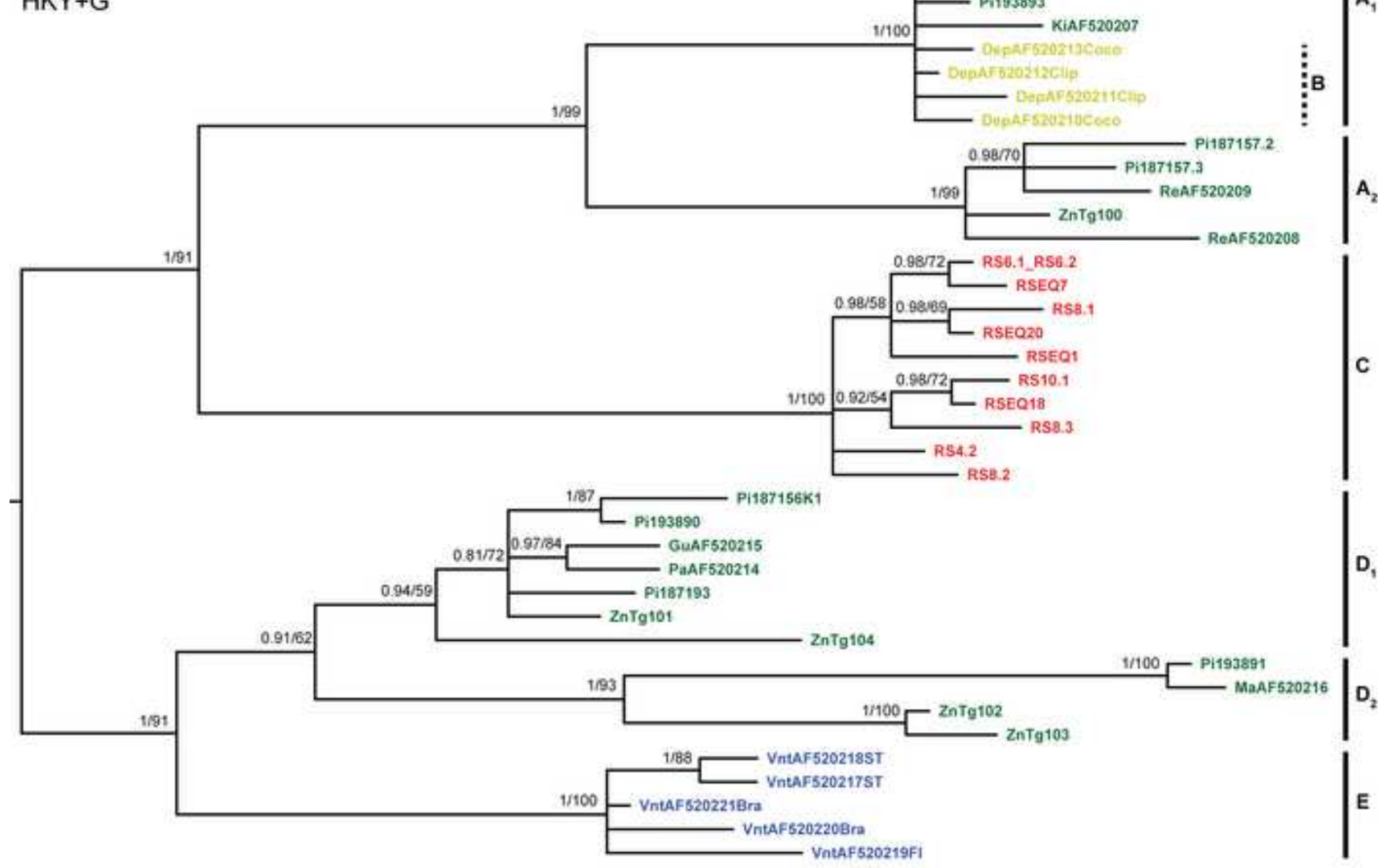



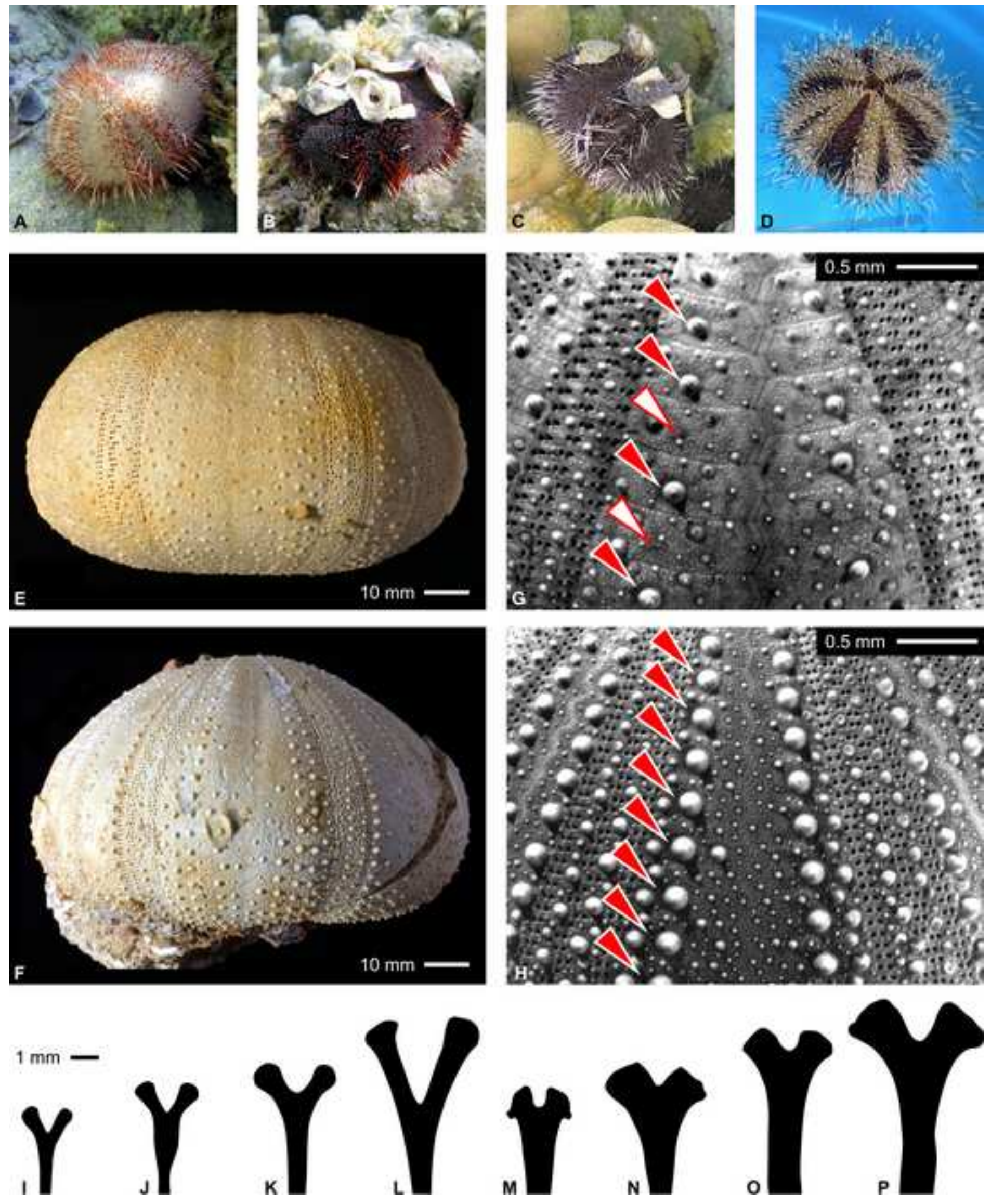

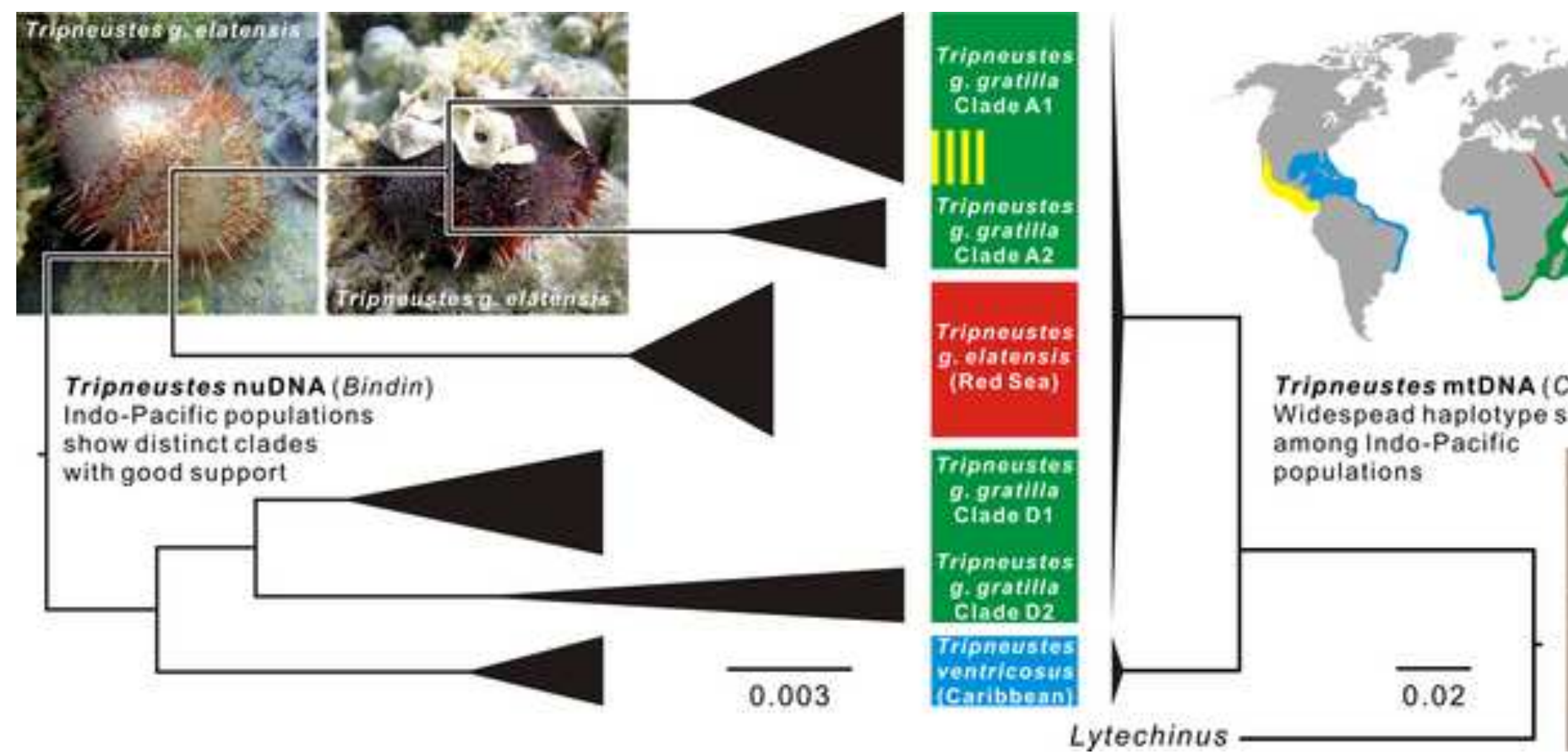

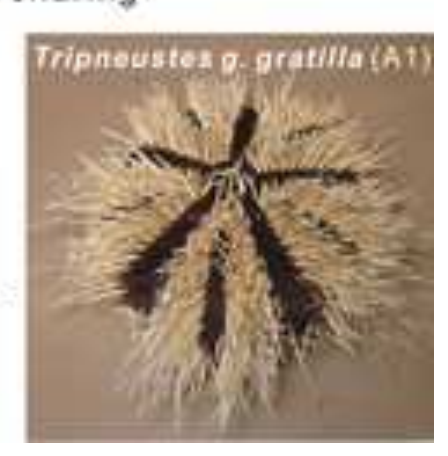

.

among Indo-Pacific

populations 